\title{
Article \\ Adder Box Used in the Heavy Trucks Transmission Noise Reduction
}

\author{
Andrei Bencze ${ }^{1}$, Maria Luminița Scutaru ${ }^{1, *}$, Marin Marin ${ }^{2} \mathbb{D}$, Sorin Vlase ${ }^{1,3}$ and Ana Toderiță ${ }^{1}$ \\ 1 Department of Mechanical Engineering, Transilvania University of Brașov, B-Dul Eroilor 20, \\ 500036 Brașov, Romania; andrei.bencze@unitbv.ro (A.B.); svlase@unitbv.ro (S.V.); \\ ana.toderita@unitbv.ro (A.T.) \\ 2 Department of Mathematics, Transilvania University of Brașov, B-Dul Eroilor 20, 500036 Brașov, Romania; \\ m.marin@unitbv.ro \\ 3 Romanian Academy of Technical Sciences, B-Dul Dacia 26, 030167 Bucharest, Romania \\ * Correspondence: 1scutaru@unitbv.ro; Tel.: +40-722-643020
}

Citation: Bencze, A.; Scutaru, M.L.; Marin, M.; Vlase, S.; Toderiță, A. Adder Box Used in the Heavy Trucks Transmission Noise Reduction. Symmetry 2021, 13, 2165. https:/ / doi.org/10.3390/sym13112165

Academic Editor: Jan Awrejcewicz

Received: 24 October 2021

Accepted: 8 November 2021

Published: 11 November 2021

Publisher's Note: MDPI stays neutral with regard to jurisdictional claims in published maps and institutional affiliations.

Copyright: (c) 2021 by the authors. Licensee MDPI, Basel, Switzerland. This article is an open access article distributed under the terms and conditions of the Creative Commons Attribution (CC BY) license (https:// creativecommons.org/licenses/by/ $4.0 /)$.

\begin{abstract}
The paper aims to analyze the vibrations of a summing box, used in heavy vehicles. An experimental setup is proposed and used for the analysis of these vibrations transmitted by the box housing, based on the measurement of the mechanical impedance. It is then shown that a simpler measurement, namely that of the generated noise spectrum, can provide equally useful results, with less effort and in a shorter time. The experimental setup is much simpler, involving a sonometer arranged in the experimental assembly. The symmetry of the box allows us to facilitate the execution of the experimental assembly, and the use of the symmetrical structure to facilitate the calculation of vibrations. The results obtained using this method in the case of a redesigned adder box are presented in the paper.
\end{abstract}

Keywords: adder box; heavy truck; transmission; noise reduction

\section{Introduction}

In the construction of trucks, regardless of their destination, in addition to the constructive, functional and reliability parameters necessary for a truck, the level of noise produced and its influence on the operation and reliability of the vehicle but especially on the environment must be taken into account. The identification of noise-generating sources depends on the complexity and specificity of the source, and is conducted by the appropriate methodology, which is based on a combination of analytical calculations of dominant frequencies with the results of experimental measurements (identification of maximum measured spectra). The quality of identifying and diagnosing noise sources increases with the improvement of the measurement technique, and especially of the processing of the measured quantities but also of the calculation models used. The noise level is an essential parameter in assessing the quality of vehicles. The main noise sources of the vehicle can be classified into:

$>$ Internal sources: the internal combustion engine, operation of the auxiliary systems of the power group (cooling, intake, exhaust), the transmission units (gearbox, PTO shaft, differential mechanism).

$>$ External sources, induced by the macro and micro road profile, stiffness of the tread, aerodynamic forces, vibration of the cab, body and side walls of the platform.

The attenuation of the noise generated by the adder box must take into account:

(1) Noise attenuation by influencing the generation mechanism.

(2) Reduction of noise transmission.

(3) Reduction of acoustic radiation by acoustic absorption.

From the point of view of the generating mechanisms, the noise sources of the adder box can be grouped into two main components. 
$>$ Noise generated by the box itself (noise due to gears and bearings when transmitting torque).

$>$ Noise radiated by the surfaces of the adder box housing.

$>$ Noise radiated from the surfaces of all accessories mounted on the box; noise that is generated by the vibration of their structures transmitted by the box, as well as by their operation.

Research has been done and is being done on the attenuation of the noise generated by the adder box, due to the gears, bearings and frictions between the mechanisms inside the box. In this paper, we refer to ways and procedures to reduce noise produced by the housing structure (structural noise), but there are no multiple reduction possibilities, especially for large components. The main reason is economic and technological because the reduction of structural noise is achieved by stiffening. This leads to additional costs for materials and changes in manufacturing and assembly technology.

An objective assumed by the designer is the constructive improvement of the structure of the adder box, so that it reduces the vibrations of the external surfaces with as little constructive and technological changes as possible and at minimal costs.

For the vehicle on which this adder box is mounted, there is a major desideratum: reducing the weight as much as possible, and therefore the weight of the box, without increasing its noise level.

Figure 1 shows the special heavy vehicle, fully equipped to be used for oil exploitation, which also includes the summing and distribution box CSD 4000, the object of this work.

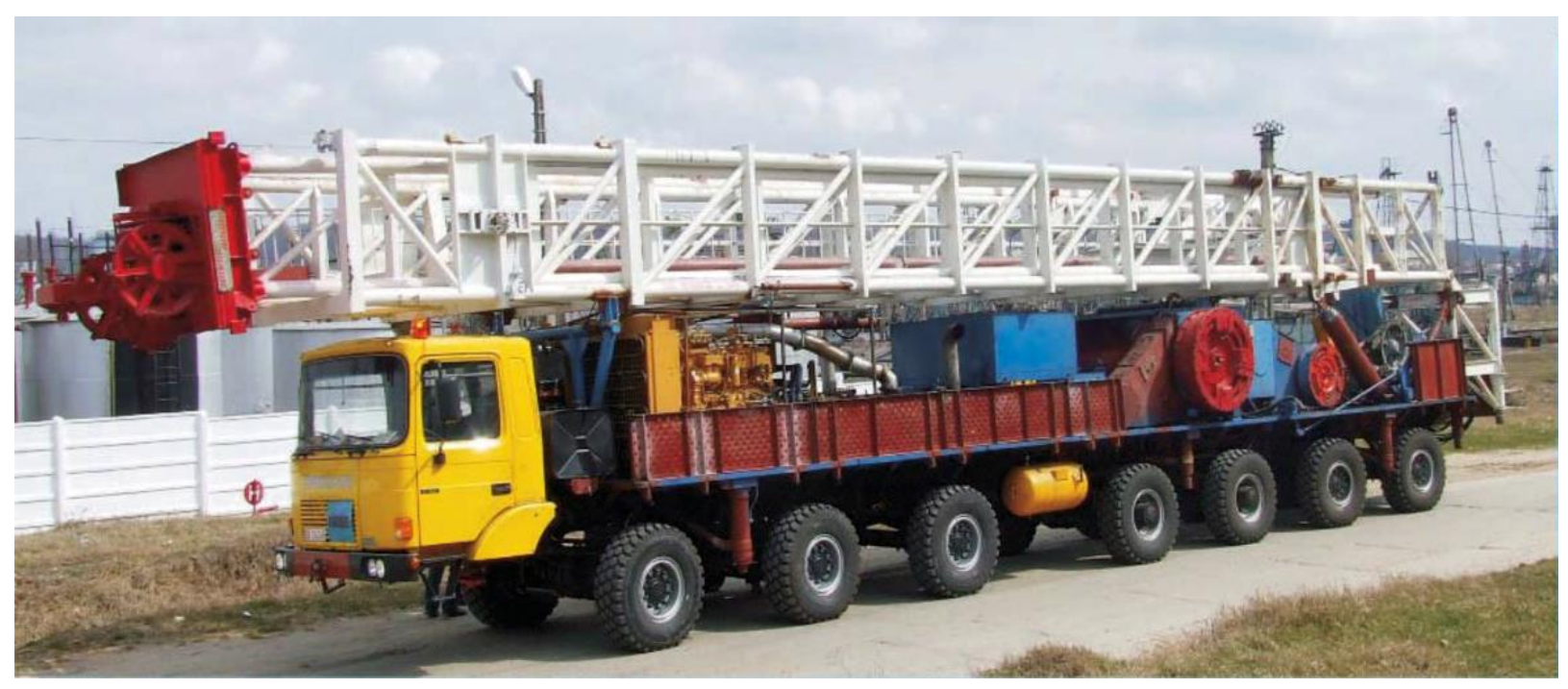

Figure 1. Special vehicle for oil exploitation.

Figure 2 summarizes the causes and possible sources of structural noise produced in the adder box.

Mechanical transmissions, similar to any other aggregate of vehicles, produce air noise perceived by the human factor as often annoying, which is noise produced by the structures of the aggregates and the functionality of the components in rotation, friction or vibration. The noise radiated by the mechanical transmissions (gearboxes, distribution, connecting elements, drive shafts or final transmissions) is influenced by the judicious choice of parameters and basic design characteristics imposed by considerations of performance, power, weight and reliability. A proper choice of these alternatives, right from the design phase, can reduce both noise and improve the performance of components and the vehicle as a whole. 


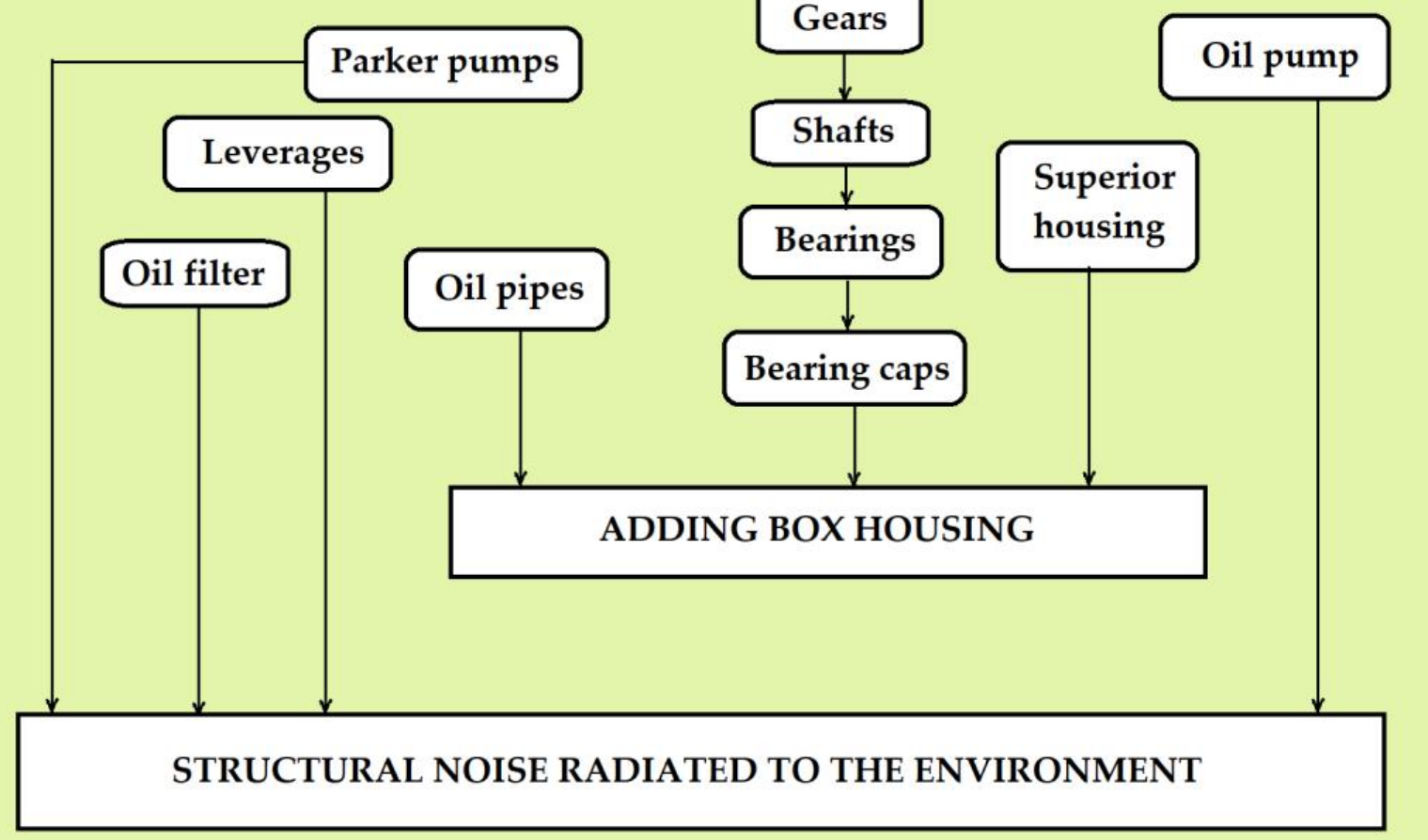

Figure 2. Causes and possible sources of structural noise.

The adder box is a mechanical construction and part of the transmission of heavy trucks which sums up the power of the two heat engines and then distributes it to the drive axles. This adder box will ensure the movement of the vehicle on the ground, during transport or the operation of a wide range of work units that are mounted on the chassis. In our case, these aggregates will drill and extract oil. The power developed by the two engines, and which is transmitted through the adder box is, in our case, 40,000 Nm.

Figure 1 shows such a vehicle, equipped to be used for drilling operations. Based on the research, an improved version will be proposed, which will then be studied in parallel with the old version. We propose that the new version reduces the structural noise of the adder box.

The main problem that occurs in the operation of heavy vehicle transmissions is the vibrations that occur and are transmitted outside [1-3]. The reduction of these vibrations and as a consequence of the noises produced by such an installation, represents a major objective of the car manufacturers. Vibrations also lead to overloads and malfunctions of the transmission assembly, which can lead to wasted time with repairs and decommissioning of vehicles. Vibration analysis of such a structure and monitoring of operation can lead to the early detection of defects and deviations from normal operation. If you study a gearbox, it is found that vibrations caused by two types of excitation sources are important. First of all is the internal excitation, due to the gears and the transmission of the moments through them, and secondly the external excitation, due to the active moments produced by the motors. The paper [4] presents a model that studies these types of vibrations, in high-speed trains, where multibody mechanical systems are used.

Such a model may take into account the elastic deformation of the wheel set and the gearbox housing. The software used was MATLAB/Simulink. The theoretical results obtained were verified experimentally. The gearbox of a heavy truck is a massive aggregate, important both for the operation of the truck but also in terms of the price of this unit. At the same time, there are some important factors for such a vehicle, such as comfort and durability, which are determined by the vibration of the transmission. In [5], the study was 
dedicated to improving the design of a planetary gearbox by reducing its weight, but at the same time having a good behavior in terms of vibration and overload.

In [6] a gearbox was analyzed, and interesting solutions were proposed to control the transmission of power flow and a calculation method was presented to provide predictable results. Experimental results demonstrated the validity of the presented dynamic model. Vibration was one of the main causes of gearbox noise [7]. As a result, there have been numerous works that have analyzed the vibrations produced, both from an experimental point of view and from a theoretical point of view. The models proposed in these papers were verified by experiments [8,9]. A series of papers [10-13] developed useful models tested experimentally.

The use of the established method of modal analysis is presented in [14-17]. A method of analysis, which uses active control systems, is presented in [18-20]. Although sustained research is being done to attenuate the noise due to the vibrations that appear in the transmission, the possibilities of reduction are minimal. The reduction of structural noise can be achieved, in most cases, by stiffening (adding masses), which leads to increased costs for materials and changes in manufacturing and assembly technologies. Therefore, other solutions are needed to improve the adder box structure, with minimal constructive and technological changes and at a minimum financial cost.

The structural analysis is performed with the finite element method, accompanied by the experimental determination of the characteristics of the housing material and its resistance limit. The proposed experimental method, applied in the research of the adder box housing can also be used to study other components or structures of the vehicle that are sources of noise. The method can therefore be used to study the auxiliary systems of the power group (gearbox, gears, cardan shaft and differential mechanism), the various housings, chassis, cab, body and side walls of the platform. Thus, it proves to be useful and with a wide field of applicability. The symmetry of the box allows us to facilitate the execution of the experimental setup and the use of the symmetrical structure to facilitate the calculation of vibrations.

The changes made to the adder box structure CSD 4000 are presented. Following the analysis of the experimentally obtained results, comparative tests on the two variants of the box (modified versus initial) were conducted in order to have an experimental validation. The main objectives of the paper are:

$>$ To analyze of the problem of noise generation, transmission and attenuation in the housing structure of heavy trucks;

$>$ To analyze of the causes and noise sources of adder gearboxes;

$>$ To conduct experimental measurements of the basic parameters of the vibration of the housing structure of the adder box (resonant frequencies, mechanical impedances);

$>$ To analyze of the results of the experimental determinations and presentation of the solutions for modifying the housing of the adder box;

$>$ To compare experimental determinations made by stand testing the adder box in the existing case and the adder box in the modified case.

\section{Noise Transmission in the Housing Structure of the Adder Box}

\subsection{Primary Calculus Model}

The adder box has a structure that can be divided into two basic parts:

(1) The moving part, which includes the gears, shafts, bearings, the differential as a whole, the oil pump, the drive pumps, other units on the chassis and the control levers;

(2) The fixed part, comprising housing, bearing covers, lubrication and cooling system pipes, filter, measuring devices, other attachments.

In all mechanical transmission units, the gear wheels represent the strongest excitation. To date, researchers' attention has been focused on obtaining gears that meet modern design, execution and assembly criteria in terms of generating and transmitting airborne and/or structural noise. 
Reductions in mechanical excitation, from the point of view of acoustic optimization, are possible, but due to considerable costs and for technical and manufacturing reasons, they can only be made up to a certain limit.

So, a reduction in mechanical excitation is limited for technical and economic reasons. However, it becomes particularly important to improve the structure of the adder box, especially the housing, so that it has as little vibration as possible on the outer surfaces, thus obtaining a significant attenuation of the structural noise. A vibration analysis involves establishing the following system properties:

- $\quad$ Eigenfrequencies $\omega_{n}$;

- Configuration of normal vibration modes $D_{j n}$;

- Damping of different modes of vibration;

- Mass distribution $m_{j}$.

The characteristic properties of the vibration eigenmodes can be determined experimentally or analytically. In the case of free vibration, if the external forces are zero and the damping is neglected, the equation of motion becomes:

$$
m_{j} \ddot{x}_{j}+\sum_{k} k_{j k} x_{k}=0
$$

The solutions of Equation (1) are of the form:

$$
x_{j}=D_{j} \sin (\omega t+\phi) \text {. }
$$

By replacing the expression (2) in (1) we obtain the equation:

$$
m_{j} \omega^{2} D_{j}=\sum_{k} K_{j k} D_{k}
$$

which represents a system of $n$ algebraic equations with $n$ unknown (eigenmodes). The solution of the system for values of $D$ other than zero is obtained by canceling the determinant:

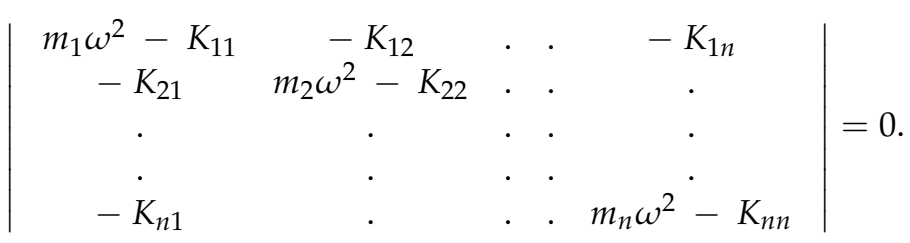

The number of degrees of freedom of a physical system is equal to the number of its eigenfrequencies. Thus, a system with distributed parameters has an infinite number of eigenfrequencies. At some point, such a system will vibrate, usually with appreciable amplitude, only at a limited number of frequencies, often at one. Each natural frequency will correspond to a form of vibration, called the normal or eigenmode of vibration. Any possible free vibration of any linear system can be formed by vibrations in superimposed eigenmodes at the corresponding eigenfrequencies. At some point in the system, the resulting motion will be the sum of the motions due to the vibrations of the component modes. Thus, a mechanical system that vibrates freely with only one of its eigenfrequencies has a distribution of amplitudes called its eigenmode of vibration, which is defined by a string of values, $D_{j n}$, (solutions (2)) that satisfy the Equation (3) when $\omega=\omega_{n}$ :

$$
\omega_{n}^{2} m_{j} D_{j n}=\sum_{k} K_{j n} D_{k n}
$$

In the vast majority of cases, the damping that occurs in elastic systems is of a viscous (or fluid) nature, i.e., the damping forces (moments) are proportional to the relative speed. 
The energy dissipated by damping is proportional to the disturbing frequency. However, in many mechanical systems, damping is frequency independent. For a more correct representation of the structural damping, the following expression was introduced:

$$
k \cdot g=c,
$$

wherein $g=\frac{2 \cdot \zeta \cdot \omega}{\omega_{n}}, \varsigma=\frac{c}{c_{c}}$ and $c_{c}=2 \sqrt{m \cdot k}=2 \cdot m \cdot \omega_{n}, \mathrm{c}$ is the damping coefficient, $c_{\mathcal{C}}$ is the critical damping coefficient and $\varsigma$ represents the fraction of the critical damping.

Thus, the damping force is equal to the viscous force at the respective frequency, depending on the value of $g$, and is independent of frequency.

The graphic between the damping force and the displacement is that of an ellipse, and the displacement response is given by the relation:

$$
\frac{x}{F_{0} / k}=R_{g} \sin (\omega t-\phi)=\frac{\sin (\omega t-\phi)}{\sqrt{\left(1-\omega^{2} / \omega_{n}^{2}\right)^{2}+g^{2}}},
$$

wherein $R g$ is the amplification factor at resonance $R_{g}=1 / \mathrm{g}$.

\subsection{Mechanical Impedance}

Mechanical impedance is a measure of the response of a mechanical system following the action of a sinusoidal excitation force [21]. The mechanical impedance is equal to the ratio between the excitation force acting on a system and the velocity of a point of the system, having a unit of measure $\mathrm{Ns} / \mathrm{m}$.

If force and velocity are measured at the same point, the impedance is called point impedance and describes the ability of the structure to resist or absorb a vibration, and if the structure response is measured at a different point as the excitation point, the impedance is called the transfer impedance and describes the ability of the structure to transmit or isolate a vibration. From the definition of impedance, it appears that in order to be able to be set in motion, a system (structure) or a mechanical element with a high impedance requires a high force, while in the case of a low impedance, in order to acquire a certain movement, the system needs a little force. Methods based on the use of mechanical impedance allow the determination of forces and motions in one or more points of a system of particular interest, without studying the whole system.

The mechanical impedance $Z$ is expressed by the relation:

$$
Z=\frac{F}{v}
$$

wherein $F$ is the applied force and $v$ the resulting velocity in the direction of the force.

\subsection{Accoustic Intensity}

Acoustic intensity I represents the continuous flow of power eliminated by an acoustic wave through the surface unit at a point in space and is expressed in $\mathrm{W} / \mathrm{m}^{2}$. This size is important for two reasons. First, a point in the free space can express the total power radiated into the air by an acoustic source, and second, it provides an expression for determining the sound pressure.

The acoustic intensity at a point is a vector in the sense that the position of the plane of the surface unit may vary between a position perpendicular to the direction of propagation of the acoustic wave and a parallel position. It has the maximum value $I_{\max }$ when this plane is perpendicular to the direction of propagation and the value zero when the plane is parallel. 
In a space where there are no reflective surfaces, at any point and for any type of propagation (plane, spherical, cylindrical, etc.) of the wave, the sound pressure is expressed as a function of the maximum intensity $I_{\max }$ by the relation:

$$
p_{\text {rms }}^{2}=I_{\max } \cdot \rho \cdot c
$$

where $p_{r m s}$ is the mean square root (MSR) of the sound pressure, in N/m $\mathrm{m}^{2}$ or $\mathrm{Pa}, \rho$ represents the density of air, in $\mathrm{kg} / \mathrm{m}^{3}$ and $c$ is the speed of sound in air, in $\mathrm{m} / \mathrm{s}$ and which represents the connection between the pressure and acoustic intensity.

The acoustic power $W_{s}$ represents the total power radiated by an acoustic source in the environment and is expressed in W. For a spherical acoustic source (with nondirectional radiation), the measured acoustic intensities (maximum) at all points of an imaginary spherical surface located in the acoustic center are equal. The mathematical relationship is:

$$
W_{s}=4 \pi \cdot r^{2} \cdot I_{S}(r)[\mathrm{W}]
$$

wherein, $I_{S}(r)$ is the maximum sound intensity at the distance $r$, in $W\left(\omega_{n}\right), W_{s}$ represents the total sound power radiated from the source, in $W$ or $W(\omega)$ and $r$ is the distance to the acoustic center of the source, in $m$.

The acoustic spectrum represents the dependence of the amplitude of an acoustic quantity of frequency. An acoustic wave can be a pure tone (a single frequency, for example $1000 \mathrm{~Hz}$ ), a combination of harmonically composed frequencies or a combination of nonharmonically composed frequencies, each in a finite or infinite number. A combination of a finite number of tones forms a spectral line and a combination of an infinite (large) number of tones forms a continuous spectrum. The continuous spectrum of a noise in which the amplitudes over time are in a normal (Gaussian) distribution is called random noise.

There are four types of sound pressure spectra: (a) harmonic spectral line; (b) nonharmonic spectral line; (c) continuous spectrum; (d) complex spectrum. A combination of a spectral line and a continuous spectrum forms a complex spectrum.

A continuous spectrum can be represented by a large number of pure tones between two limit frequencies. Because the human ear perceives a wide range of frequencies and does not have the same sensitivity for all frequencies, the continuous acoustic spectrum is usually measured in a series of adjacent frequency bands using an acoustic analyzer.

Usually, the width of the frequency band used is $1 / 3$ octave and 1 octave. If the width of the filter band is $1 \mathrm{~Hz}$, the graph of the sound pressure in SMR values (square mean roots), thus filtered of a continuous acoustic spectrum in frequency, is called the power spectral density. The square mean root of the sound pressure can be determined for each of the adjacent frequency bands and the result can be viewed graphically by frequency.

\subsection{Generation and Transmission of Structural Noise}

Impedance $\mathrm{Z}$ characterizes the resistance of the mechanical structure to the excitation of an oscillating force acting at the excitation point. Impedance is called point impedance if the area through which the force excites the structure is less than 1/6 of the relevant wavelength (bending or shear wave).

An easy way to make changes to the excitation point impedance of a real structure is to add masses to the structure. The local application of a mass and/or the increase in the rigidity will determine a displacement of one or more eigenfrequencies towards the range of low frequencies and a possible reduction in the specific noise sources. The use of additional damping can have a similar effect but mainly leads to reduced resonance peaks. In the field of multiple resonances, adding masses or increasing the stiffness of specific components is very effective. For example, the addition of a mass on the surface of the structure leads to the displacement of the first eigenfrequency of the structure towards low frequencies and consequently to the reduction in the level of surface velocity in the range of resonant frequencies. Increasing the rigidity of the structure is effective in the field of multiple resonances, only in the case of excitation by force and without effect in the case of 
excitation by speed. Table 1 summarizes the noise control measures for the three response domains obtained by changing the excitation point impedance.

Table 1. The noise control measures for the three response domains.

\begin{tabular}{clll}
\hline Excitation Type & \multicolumn{1}{c}{ Quasistatic } & \multicolumn{1}{c}{ Resonant } & \multicolumn{1}{c}{ Multiresonant } \\
\hline \multirow{2}{*}{ Excitation by force } & $\begin{array}{l}\text { Masses are added } \\
\text { Add rigidity }\end{array}$ & $\begin{array}{l}\text { Add masses } \\
\text { Add rigidity } \\
\text { Add damping }\end{array}$ & $\begin{array}{l}\text { Add masses } \\
\text { Add rigidity } \\
\text { Add damping }\end{array}$ \\
\hline \multirow{2}{*}{$\begin{array}{c}\text { Excitation through } \\
\text { speed }\end{array}$} & $\begin{array}{l}\text { An elastic spring is } \\
\text { inserted and masses } \\
\text { are added or rigidity } \\
\text { is added to the } \\
\text { structure }\end{array}$ & $\begin{array}{l}\text { An elastic spring is } \\
\text { inserted and masses } \\
\text { are added or rigidity } \\
\text { is added to the } \\
\text { structure }\end{array}$ & $\begin{array}{l}\text { An elastic spring is } \\
\text { inserted and masses } \\
\text { are added or rigidity } \\
\text { is added to the } \\
\text { structure }\end{array}$ \\
\hline
\end{tabular}

The construction of a gearbox, distribution or summation in this case is conceived and designed primarily for the transmission of torque.

The forces in the gears inside the housing act on the outer housing, and, through the shafts and bearings, produce bending forces that are felt by the housing. Therefore, the housing of the box will vibrate in response to its applied internal forces, and these structural vibrations will be transmitted through the structure to its outer surfaces and attached components, thus generating structural noise, and, of course, airborne noise. Although the vibrations are of very small amplitudes, they will produce very large increases in the noise level.

The transmission of vibrations produced in the structure is done mainly from the inside, i.e., from the engagement of the gears through the bearings of the shafts to the outer surfaces of the housing.

So, the structural vibrations are generated inside the box and are transmitted to the outer surfaces, with the vibratory properties of the load-bearing components being decisive in transmitting these vibrations. The resulting noise will depend on the vibration properties of the parts that make up the housing structure (gears, shafts, large cover, bearing caps, pumps and controls) as well as their individual acoustic radiation coefficient. Theoretically, the transmission of structural vibrations can be controlled by changing the natural frequencies and by increasing the damping.

The characteristics of structural vibrations are defined by the type and value of their eigenfrequencies, as well as by the damping factor. The coefficient of acoustic radiation depends on the length of the bending wave and the size of the radiating surface.

The study of the distribution of the structural noise on the surface of the box housing is particularly useful in the design of structural measures. The highest vibrations occur in the power take-off area, between the bearings of the main shaft and bearings placed on the front surface of the box, but especially in the bearing placed on the rear surface of the box. The result is typical of many types of gearboxes: the area of the highly demanded bearings is placed at a relatively large distance from the gearbox mounts on the chassis. In this situation, the amplitude of the vibrations is higher than in other areas, and the bending of the surface contributes strongly to the radiation of the noise.

Viewed in a unitary way, the construction of the adder box consists of a housing divided into compartments. The upper part of the housing is closed by the large cover, which is relatively rigid, and the lower part is closed by full sheet metal welding where we have the differential and the oil bath. Furthermore, in the upper, middle and lower parts on the housing there are the covers that support the gears. Thus, the surfaces of the box as well as the large cover, which, although having a relatively large thickness, have a reduced rigidity due to the presence of large holes through which the shafts with assembled gears must pass during assembly.

The term structural noise describes the noise generated by the vibrations inside the solid structures that are manifested in the acoustic frequency range. This noise is radiated by the outer surfaces of the structures, resulting in radiated airborne noise. In order to 
evaluate the noise radiated by the housing structure based on the appreciation of the vibrations of its external surfaces, it is necessary to know the connection between the vibration of the surfaces of the structure and the aerial noise radiated by them.

To characterize the connection between vibrations in the range of acoustic frequencies of a structure (structural noise) and radiated airborne noise (radiated acoustic power) of that surface in the environment, the notion of acoustic radiation coefficient $\sigma$ is used.

By definition, the coefficient of acoustic radiation is:

$$
\sigma=\frac{W_{r}}{W_{0}}
$$

In the practical measurements, the value of the sound pressure level $L_{p r}$ resulting from the radiated acoustic power is of interest:

$$
L_{p_{r}}=\bar{L}_{v}+\left[10 \cdot \log \left(\frac{S}{1 \mathrm{~m}^{2}}\right)+10 \cdot \log (\sigma)\right][\mathrm{dB}]
$$

where $\vec{L}_{v}$ is the average level of speed, the upper bar symbolizing the mediation, in $\mathrm{dB}, \mathrm{S}$ represents the analyzed surface, in $\mathrm{m}^{2}, 1 \mathrm{~m}^{2}$ is the reference surface and $\sigma$ is the coefficient of acoustic radiation. The coefficient of acoustic radiation $\sigma$ is mainly dependent on the shape and amplitude of the vibration. The amplitude of the vibration in turn depend on the shape of the surface and the place where the disturbing excitation is applied. In different frequency bands, the acoustic radiation is generally different. The coefficient of acoustic radiation $\sigma$ shows an increase at high frequencies and a decrease at low frequencies.

\subsection{Eigenfrequencies of the Old Version of the Adder Box}

In the case of the adder and distribution box housing, with the ABAQUS program, 105 eigenfrequencies have been determined in the frequency range 100-2000 Hz. In Table 2 are listed some eigenvibration modes, where in the first column the vibration modes are specified and in the second column the corresponding eigenfrequencies.

\begin{tabular}{|c|c|c|c|c|c|c|c|}
\hline \multicolumn{8}{|c|}{ FREQUENCY DOMAINS [Hz] } \\
\hline \multicolumn{2}{|c|}{$100-500$} & \multicolumn{2}{|c|}{$500-1000$} & \multicolumn{2}{|c|}{$1000-1500$} & \multicolumn{2}{|c|}{$1500-2000$} \\
\hline $\begin{array}{c}\text { Nr. of. } \\
\text { Eigen-Mode }\end{array}$ & $\begin{array}{c}\text { Eigen- } \\
\text { Frequency } \\
{[\mathrm{Hz}]}\end{array}$ & $\begin{array}{c}\text { Nr. of. } \\
\text { Eigen-Mode }\end{array}$ & $\begin{array}{c}\text { Eigen- } \\
\text { Frequency } \\
{[\mathrm{Hz}]}\end{array}$ & $\begin{array}{c}\text { Nr. of. } \\
\text { Eigen-Mode }\end{array}$ & $\begin{array}{c}\text { Eigen- } \\
\text { Frequency } \\
{[\mathrm{Hz}]}\end{array}$ & $\begin{array}{c}\text { Nr. of. } \\
\text { Eigen-Mode }\end{array}$ & $\begin{array}{c}\text { Eigen- } \\
\text { Frequency } \\
{[\mathrm{Hz}]}\end{array}$ \\
\hline 1 & 135 & 14 & 611 & 39 & 1019 & 76 & 1525 \\
\hline 3 & 249 & 18 & 653 & 42 & 1063 & 79 & 1607 \\
\hline 5 & 305 & 21 & 716 & 45 & 1126 & 82 & 1659 \\
\hline 6 & 361 & 22 & 778 & 48 & 1150 & 85 & 1701 \\
\hline 7 & 380 & 24 & 800 & 52 & 1200 & 88 & 1737 \\
\hline \multirow[t]{8}{*}{9} & 490 & 28 & 847 & 56 & 1244 & 91 & 1805 \\
\hline & & 33 & 904 & 60 & 1300 & 94 & 1834 \\
\hline & & 35 & 959 & 65 & 1355 & 97 & 1896 \\
\hline & & 38 & 1000 & 68 & 1412 & 98 & 1901 \\
\hline & & & & 70 & 1453 & 102 & 1936 \\
\hline & & & & 74 & 1498 & 103 & 1976 \\
\hline & & & & & & 104 & 1980 \\
\hline & & & & & & 105 & 1984 \\
\hline
\end{tabular}

Table 2. Calculated eigenfrequencies. 


\section{Results in the Generation, Transmission and Reduction of Noise}

3.1. Experimental Research Program on the Housing Adder Box

In order to improve the design of the adder box by structural measures, it is absolutely necessary to establish the criteria by which one is be able to predict, from the design phase, the vibration characteristics and the noise level radiated by the individual box structures, especially the housing structure (Figure 3).

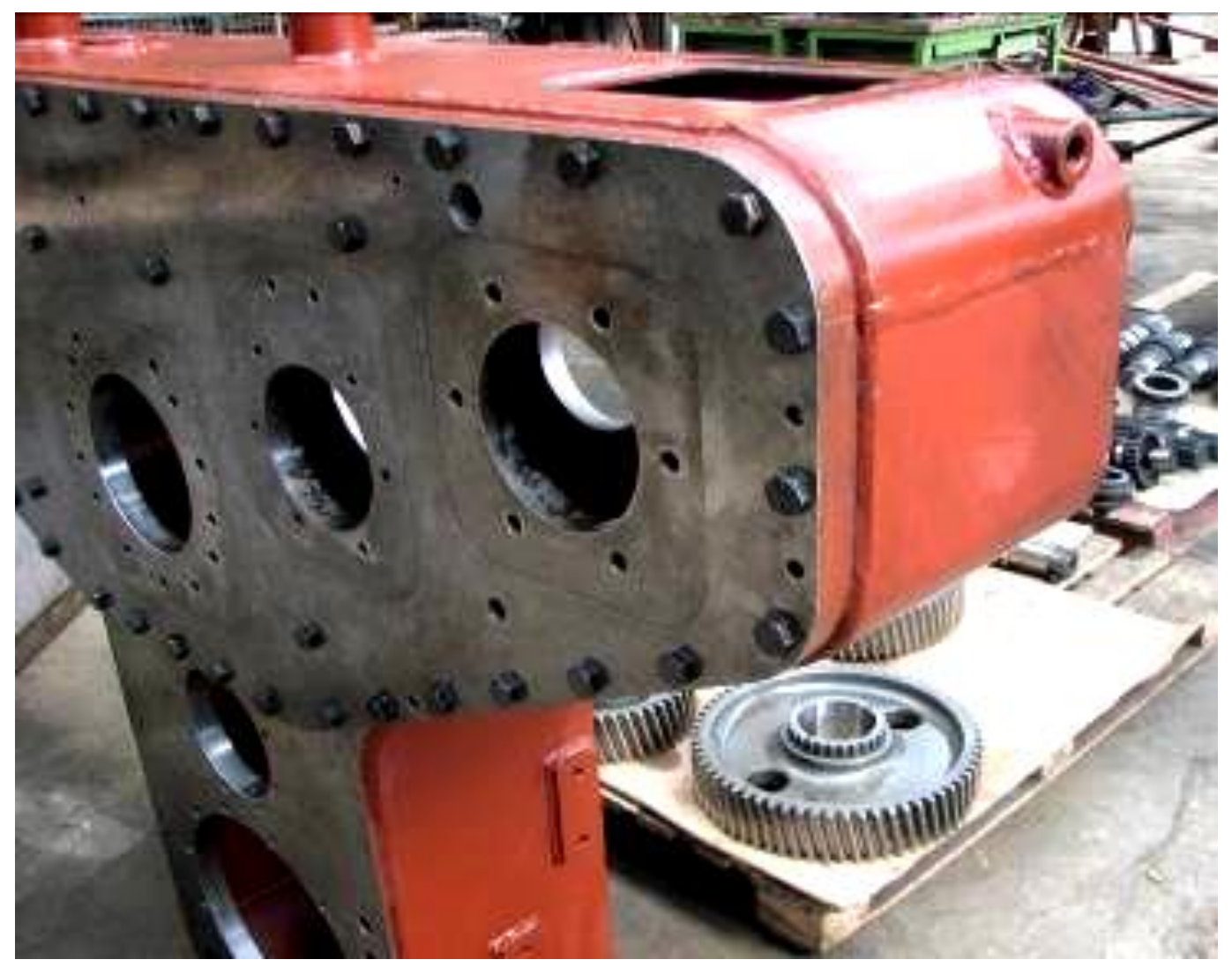

Figure 3. Adder box housing assembled with a large cover.

In the following is presented an experimental, efficient, useful and fast method for determining the noise radiated by the housing surfaces. The experimental results obtained constitute major information necessary to determine the characteristics of structural noise transmission in the housing.

The results obtained from the experiments performed on a housing from the composition and distribution box CSD 4000 are presented.

The box is intended for drilling chassis equipped with two CATERPILAR engine groups and an ALLISON automatic gearbox. The main technical characteristics of the adder box are:

- $\quad$ Maximum input moment: $2 \times 2000$ daNm;

- $\quad$ Maximum input speed: $2100 \mathrm{rpm}$;

- Transmission ratio to shaft B: 1.275;

- Transmission ratio to shaft C: 1.4;

- $\quad$ Transmission ratio to shaft E: 1.1 ;

- Own mass: approx. $1650 \mathrm{~kg}$.

The experiments were performed on the housing of the old version adder box.

The program of experimental research on the case of the adder box is presented in the block diagram from Figure 4 . 


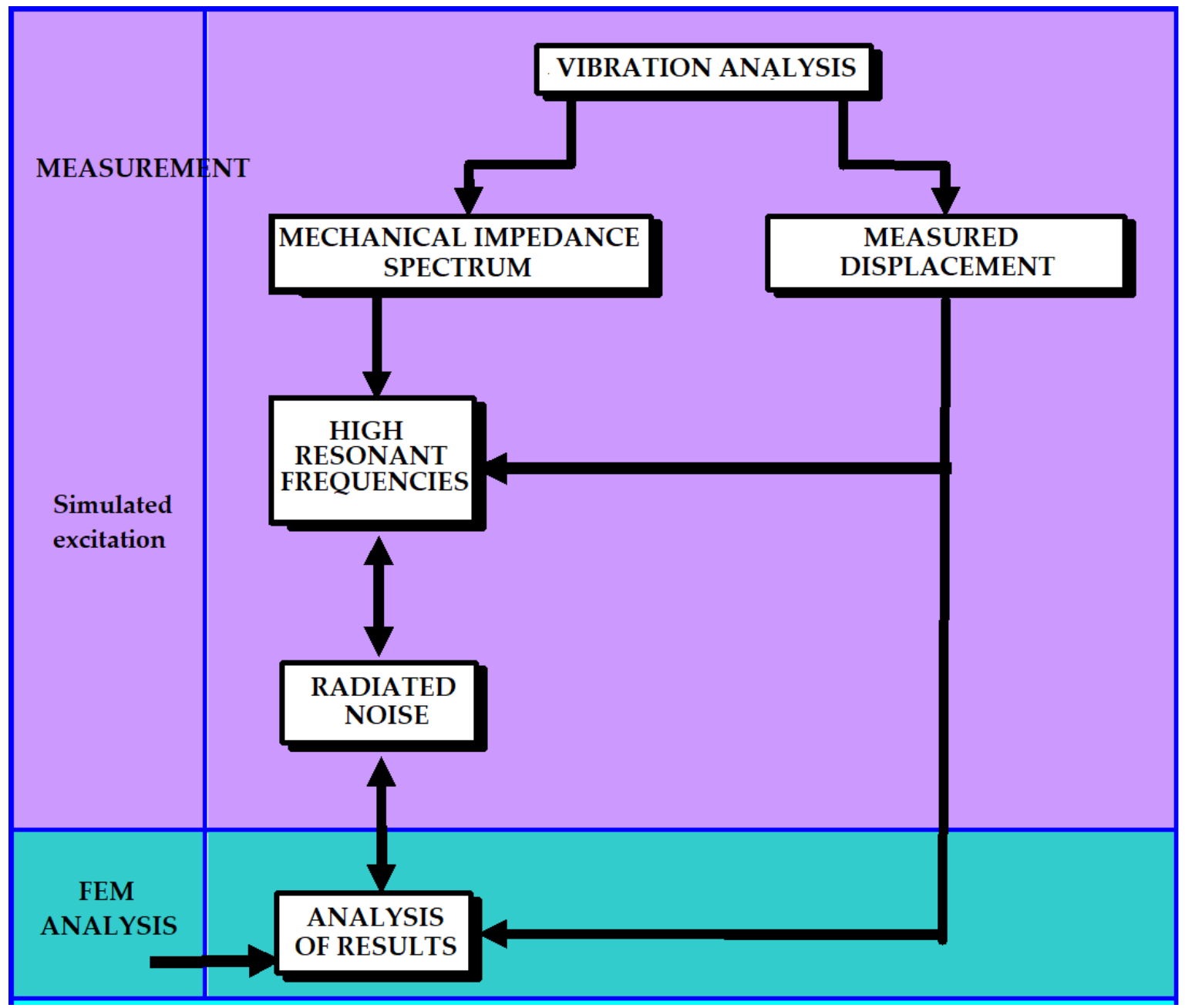

Figure 4. Block diagram of the experimental research program on the housing adder box.

The experimental research program consisted of:

(1) Experimental analysis of the vibration behavior of the structure of the adder box. The mechanical impedances corresponding to the resonant frequencies was determined;

(2) Measurement and experimental analysis of the noise radiated by the housing surfaces.

\subsection{Measurement and Experimental Analysis of the Noise Radiated by the Surfaces of the Adder} Box Housing

To perform the experiments, the housing structure of the adder and distribution box was brought into a state of simulated vibration. Furthermore, because the housing structure is much more rigid when bending in the vertical plane (parallel to the front and rear surfaces of the housing) than in the horizontal plane, the bending waves in the horizontal plane being the main causes of structural noise transmission, housing excitation was performed horizontally using an electrodynamic exciter.

The adder and distribution box is mounted on the chassis by means of screw supports, their rigidity being very high (the rubber used has high rigidity). To simulate these conditions, the analyzed housing was mounted with its mounting brackets, which are fixed on two brackets mounted on the laboratory platform, brackets that practically simulate the vehicle chassis. 
The experimental analysis of the vibration behavior of the box housing structure was performed by bringing it into a simulated vibration state in the frequency range $30 \mathrm{~Hz} \div$ $2000 \mathrm{~Hz}$.

In the experimental analysis of the vibration behavior of the box housing structure, the technique of measuring the point mechanical impedance was used, using an impedance transducer. The technique of measuring mechanical impedance was used in order to obtain complete data on the vibration behavior of a mechanical structure. The biggest advantage of the method based on the use of mechanical impedance in solving vibration problems is that it allows the determination of forces and displacements in one or two points of a mechanical structure without the need for a complete study of the entire structure. By measuring the point mechanical impedance, the ability of a structure to withstand resistance or to absorb a vibration can be determined.

The main condition is that the excitation force varies sinusoidally because the mechanical impedance is defined only for forces and velocities with sinusoidal variation.

The experimental analysis of the vibration behavior of the box housing structure using the technique of measuring the point mechanical impedance, the measurement and analysis installation is presented in Figure 5.

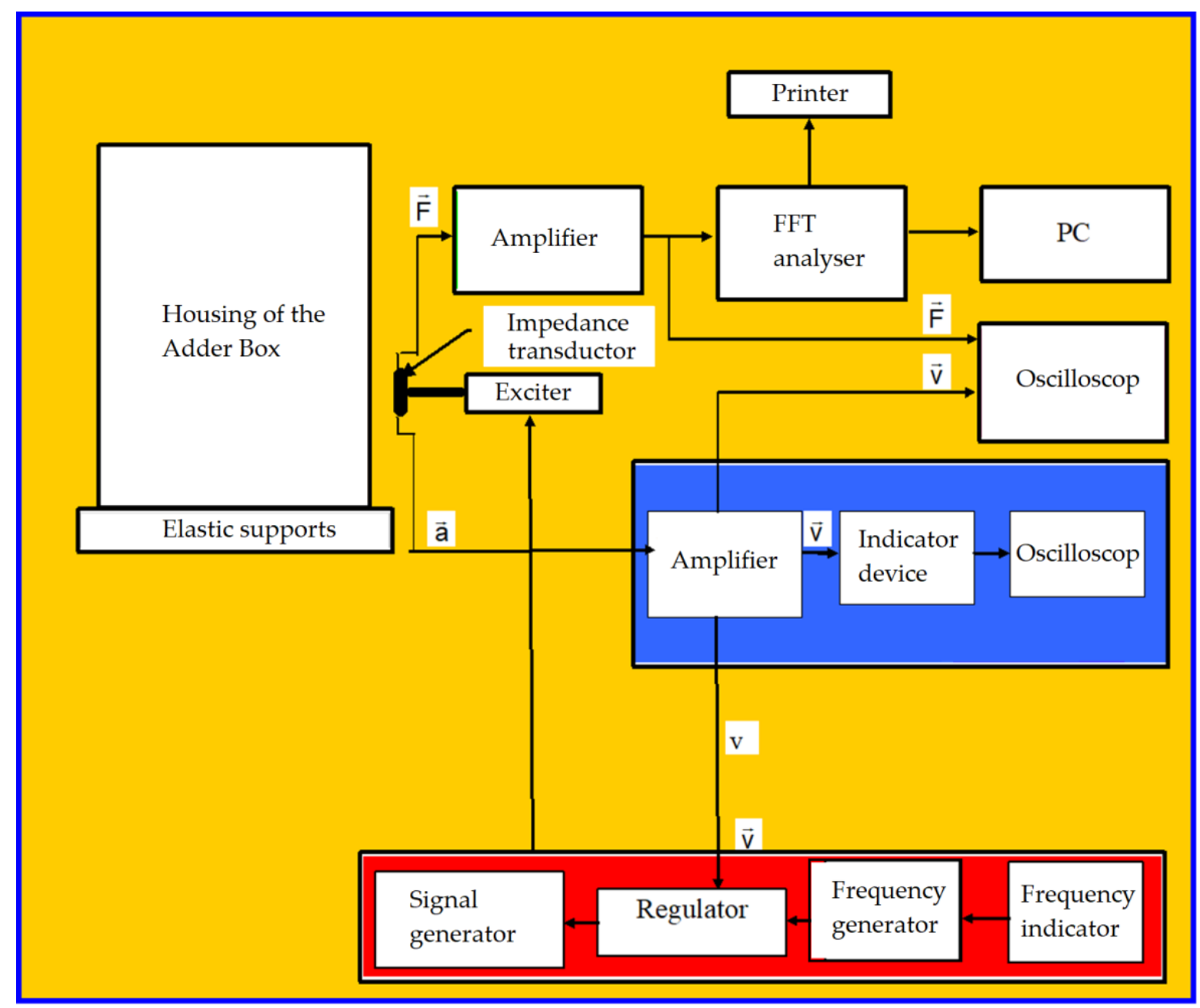

Figure 5. The measurement and analysis installation. 
The vibration of the box housing structure is taken over by the acceleration transducer, which it transforms into an electrical signal proportional to the acceleration.

The acceleration signal $\vec{a}$ is integrated with the help of the integrating amplifier to obtain a signal proportional to the speed $\vec{v}$, which is then applied to the excitation signal generating equipment thus obtaining a "feedback" type adjustment. So, the signal generator will control the action of the exciter in order to maintain a constant speed at the excitation point.

Calibration of the vibration measuring system was performed with an accuracy of $\pm 5 \%$. The force signal $\bar{F}$ was amplified and then applied to the input of the FFT (fast Fourier transform) frequency analyzer. Since the speed signal is kept constant, the force signal will be directly proportional to the numerical value of the mechanical impedance $\vec{Z}_{m}$ :

$$
\left|\vec{Z}_{m}\right|=\frac{|\vec{F}|}{|\vec{v}|}=k \cdot|\vec{F}|,
$$

where $k=\frac{1}{|\vec{v}|}=$ const., so that the power spectral density of the point mechanical impedance will be obtained at the FFT frequency analyzer.

Excitation force had the following parameters:

- $\quad$ Signal shape: sinusoidal;

- Constant speed: $v_{e x}=4 \cdot 10^{-3} \mathrm{~m} / \mathrm{s}$;

- Exponential back and forth variation of the excitation signal frequency with the speed of 1 oct/min, in two domains: $30 \mathrm{~Hz} \div 500 \mathrm{~Hz}$ with the resolution: $1.25 \mathrm{~Hz} ; 300 \mathrm{~Hz} \div$ $2000 \mathrm{~Hz}$ with the resolution: $5 \mathrm{~Hz}$.

The linearly mediated power spectral densities of the three points of the mechanical impedance on the front surface of the housing and on the rear surface of the housing (considered in normal chassis mounting) were determined experimentally. The points were chosen in the area of the two inputs in the box and in the area of the power take-off. The coordinates of the measuring points, expressed in $\mathrm{mm}$, on the two surfaces of the housing in the coordinate system (Figure 6) considered for normal mounting on the chassis are presented in Table 3.

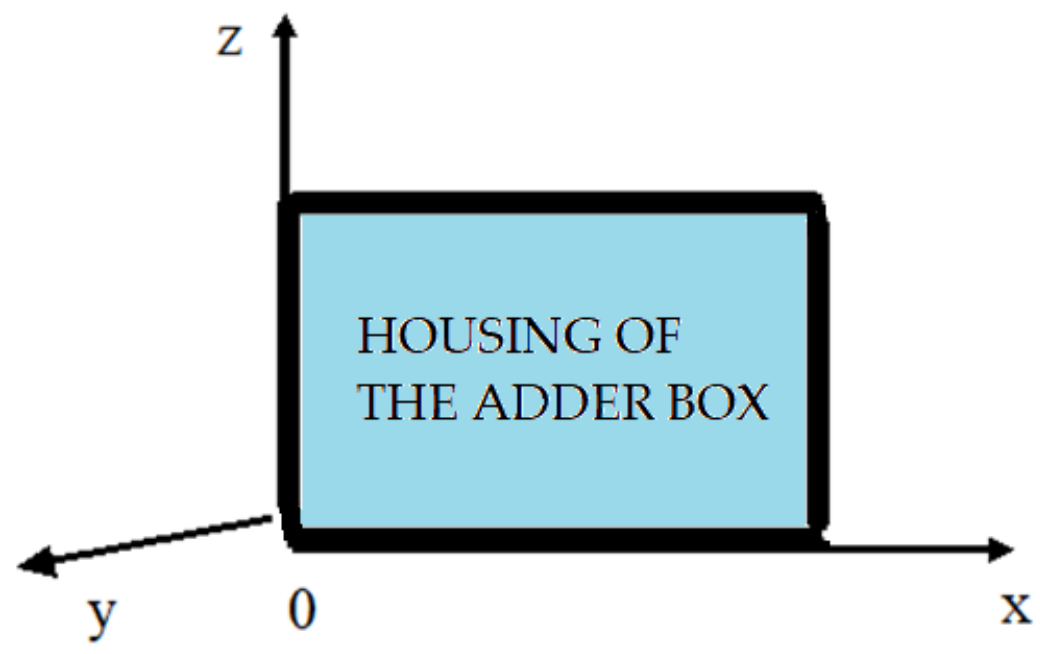

Figure 6. Coordinate frame for housing of the adder box. 
Table 3. Coordinates of measuring points 1-6 (x, z).

\begin{tabular}{cccc}
\hline \multicolumn{4}{c}{ Front Surface of the Housing } \\
\hline Frequency Range & Point 1 & Point 2 & Point 3 \\
\hline $30 \mathrm{~Hz} \div 500 \mathrm{~Hz}$ & $(500,1200)$ & $(1200,1200)$ & $(850,600)$ \\
\hline $300 \mathrm{~Hz} \div 2000 \mathrm{~Hz}$ & $(500,1200)$ & $(1200,1200)$ & $(850,600)$ \\
\hline & Rear Surface of the Housing & \\
\hline Frequency Range & Point 4 & Point 5 & Point 6 \\
\hline $30 \mathrm{~Hz} \div 500 \mathrm{~Hz}$ & $(1200,1200)$ & $(500,1200)$ & $(850,600)$ \\
\hline $300 \mathrm{~Hz} \div 2000 \mathrm{~Hz}$ & $(1200,1200)$ & $(500,1200)$ & $(850,600)$ \\
\hline
\end{tabular}

It is important to note that, unlike analyses that use the values of accelerations measured in the narrow band of frequencies where the eigenfrequencies are represented by "peaks" (maximum), in the spectrum of point mechanical impedance, the resonances appear as "valleys" (minimum). The accuracy of linearly mediated power spectral density records (2048 mediations) is $1.1 \%$ or $0.1 \mathrm{~dB}$.

The spectra of the point mechanical impedances $Z_{m}(f)$, expressed in $\mathrm{kNS} / \mathrm{m}$ and obtained following the mediation of the recordings obtained in the six measurement points corresponding to the two frequency domains, are presented in Figures 7 and 8 for the front surface of the housing and in Figures 9 and 10 for the rear surface of the housing.

The analysis of the obtained results were determined experimentally from the main eigenfrequencies and the corresponding values of the mechanical impedances of the box structure of the adder box for the two analyzed surfaces. The results are presented in Table 4.

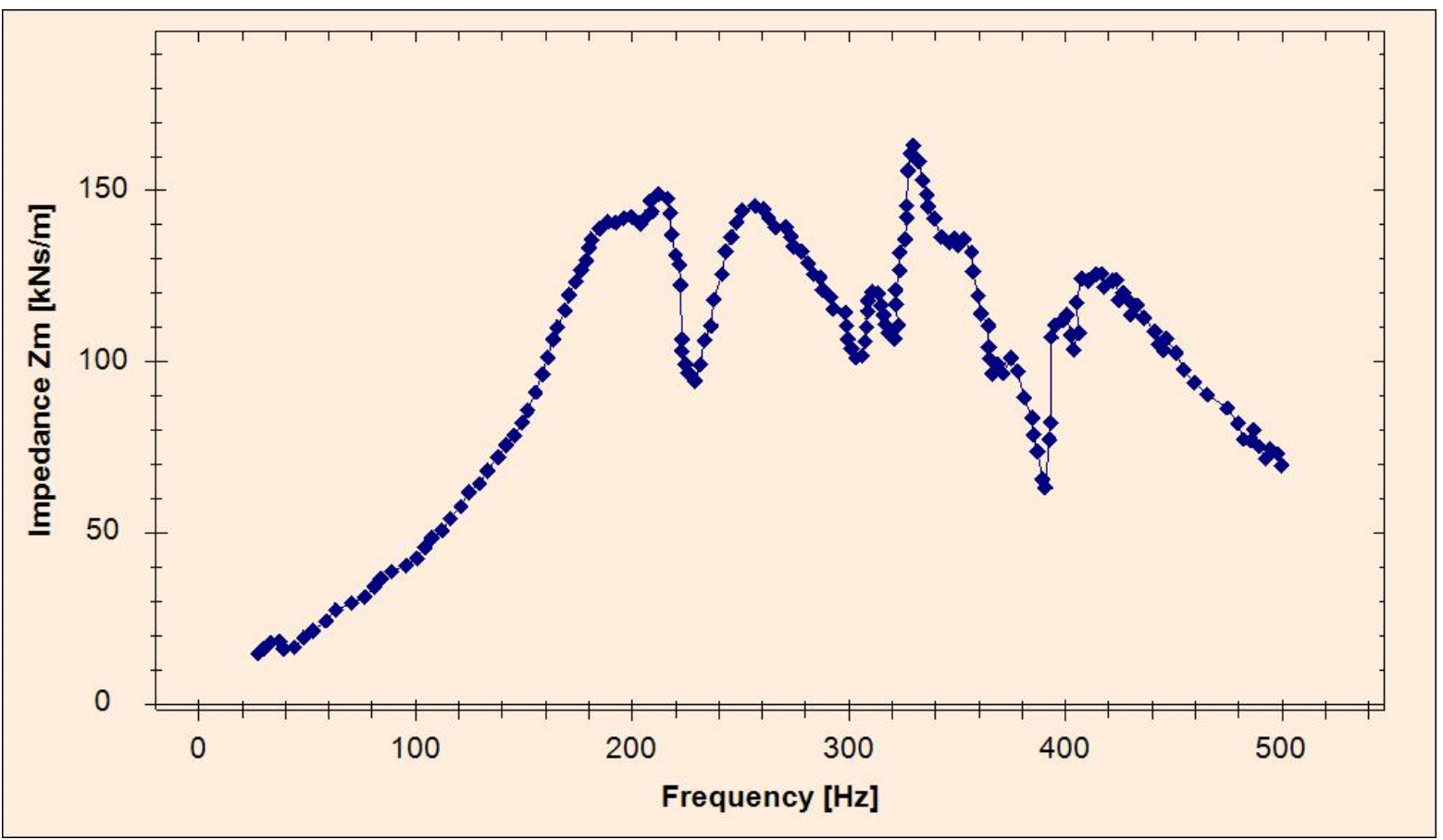

Figure 7. Spectrum of mechanical impedances of the front surface of the housing; $f=30 \mathrm{~Hz} \div 500 \mathrm{~Hz}$. 


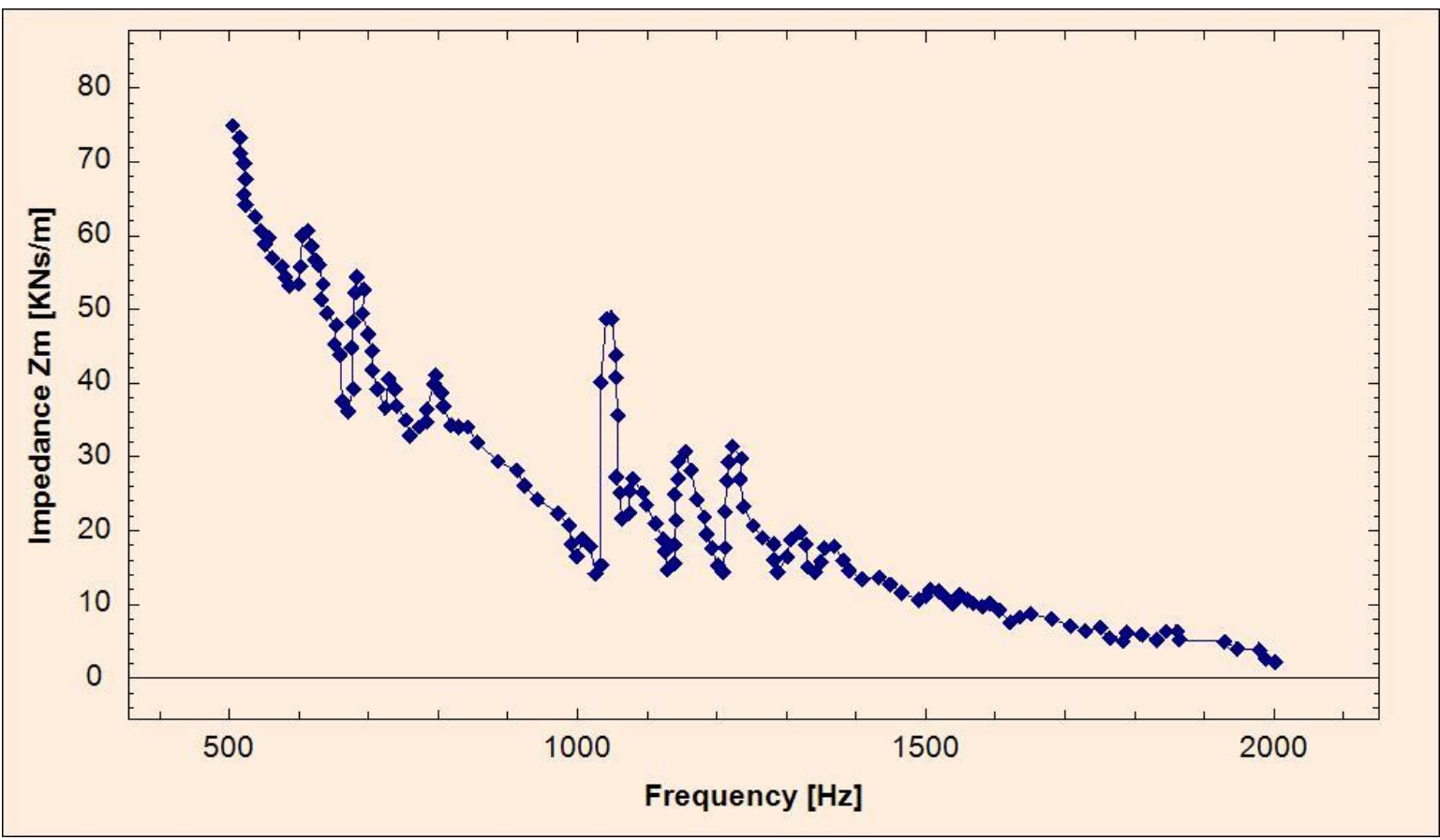

Figure 8. Spectrum of mechanical impedances of the front surface of the housing; $f=500 \mathrm{~Hz} \div 2000 \mathrm{~Hz}$.

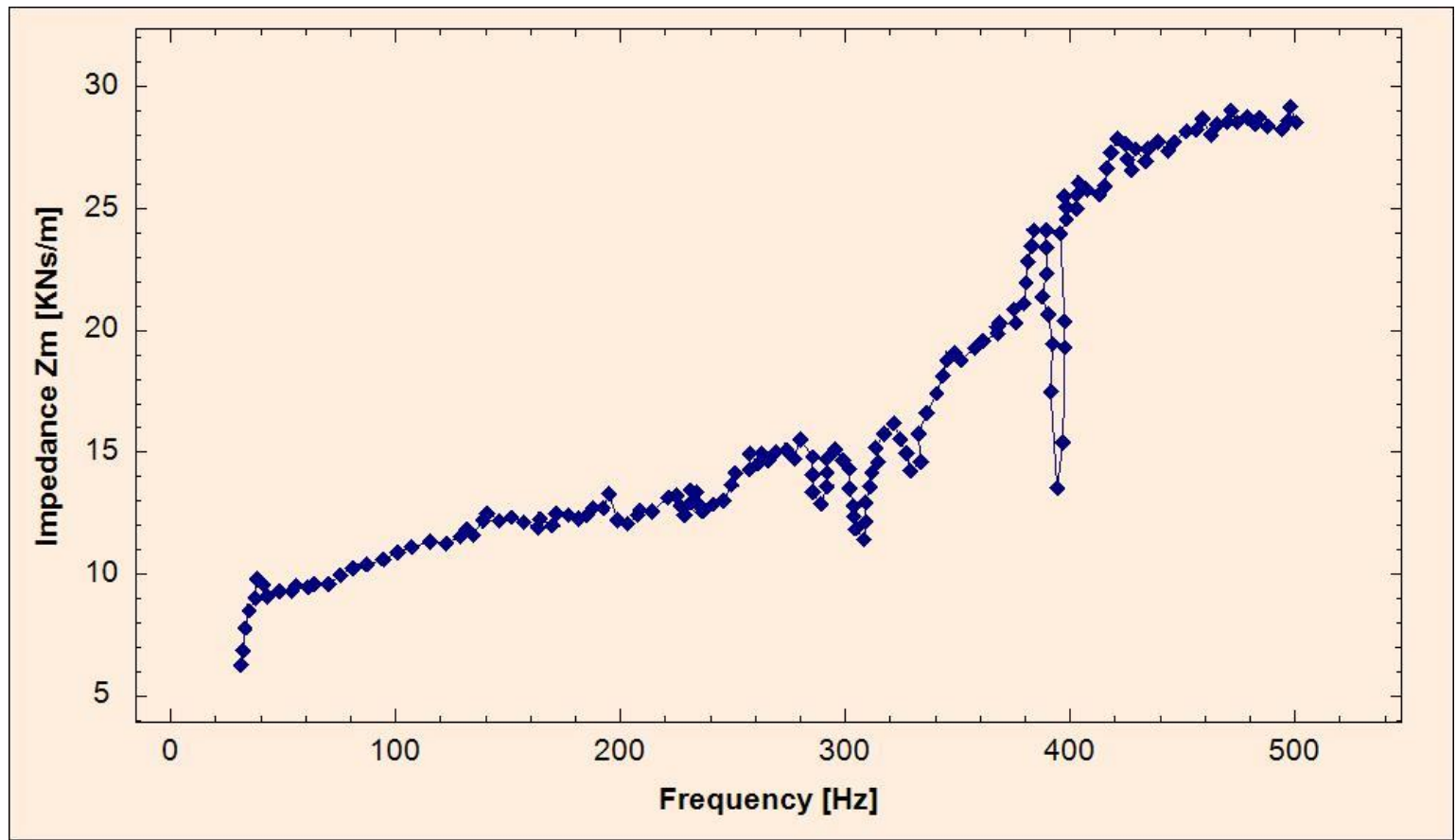

Figure 9. Mechanical impedance spectrum of the rear surface of the housing; $f=30 \mathrm{~Hz} \div 500 \mathrm{~Hz}$. 


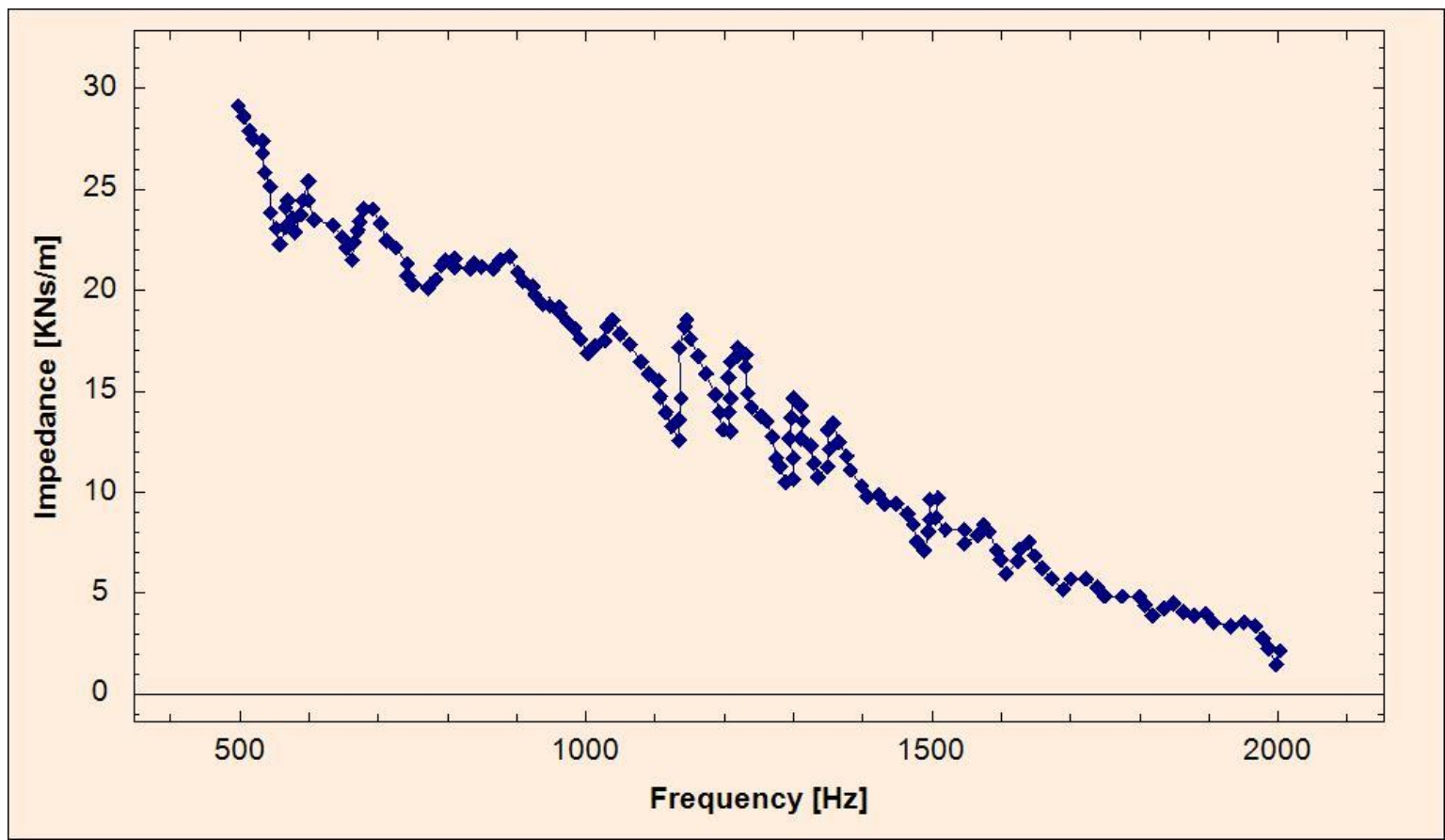

Figure 10. Mechanical impedance spectrum of the rear surface of the housing; $f=500 \mathrm{~Hz} \div 2000 \mathrm{~Hz}$.

Table 4. Eigenfrequencies and mechanical impedance values.

\begin{tabular}{|c|c|c|c|c|}
\hline \multirow[b]{2}{*}{ Frequency Range } & \multicolumn{2}{|c|}{ Front Surface of the Housing } & \multicolumn{2}{|c|}{ Rear Surface of the Housing } \\
\hline & Eigenfrequency [Hz] & $\begin{array}{l}\text { Mechanical Impedance } \\
{[\mathrm{kN} \cdot \mathrm{s} / \mathrm{m}]}\end{array}$ & Eigenfrequency [Hz] & $\begin{array}{l}\text { Mechanical Impedance } \\
{[\mathrm{kN} \cdot \mathrm{s} / \mathrm{m}]}\end{array}$ \\
\hline \multirow{10}{*}{$30 \mathrm{~Hz} \div 500 \mathrm{~Hz}$} & 230 & 96.5 & 200 & 11.5 \\
\hline & 300 & 100 & 225 & 13.2 \\
\hline & 320 & 110 & 235 & 12.9 \\
\hline & 395 & 60.5 & 280 & 14 \\
\hline & 400 & 105 & 300 & 12.5 \\
\hline & 500 & 75.5 & 330 & 15.5 \\
\hline & & & 395 & 14.5 \\
\hline & & & 410 & 25.5 \\
\hline & & & 435 & 27 \\
\hline & & & 495 & 28.8 \\
\hline \multirow{13}{*}{$500 \mathrm{~Hz} \div 2000 \mathrm{~Hz}$} & 590 & 53 & 580 & 11.5 \\
\hline & 660 & 38.5 & 640 & 10.5 \\
\hline & 720 & 37.5 & 850 & 10.2 \\
\hline & 765 & 33 & 1000 & 8.5 \\
\hline & 1010 & 13.5 & 1125 & 6 \\
\hline & 1070 & 23 & 1200 & 6.5 \\
\hline & 1145 & 17.5 & 1300 & 5.2 \\
\hline & 1200 & 16 & 1340 & 5 \\
\hline & 1300 & 15 & 1490 & 3.5 \\
\hline & 1345 & 14.5 & 1550 & 3.7 \\
\hline & 1500 & 11.5 & 1610 & 2.9 \\
\hline & 1525 & 10.5 & 1900 & 1.7 \\
\hline & 1610 & 9 & 2000 & 0.9 \\
\hline
\end{tabular}


It was found that the eigenfrequencies of the structure of the adder box are approximately in the range of $250 \mathrm{~Hz} \div 2000 \mathrm{~Hz}$, with a dominant frequency of $395 \mathrm{~Hz}$ for both the front and the back housing surface of the adder and distribution box.

\subsection{Measurement and Experimental Analysis of the Noise Radiated by the Surfaces of the Adder Box Housing}

The measurement of the radiated noise (sound pressure level) of the adder box housing surfaces was performed by bringing it to a state of simulated vibration in the frequency range $30 \mathrm{~Hz} \div 2000 \mathrm{~Hz}$. For the measurement sound pressure level radiated, the measurement and analysis installation is presented in Figure 11. The experimental setup is presented in Figure 12.

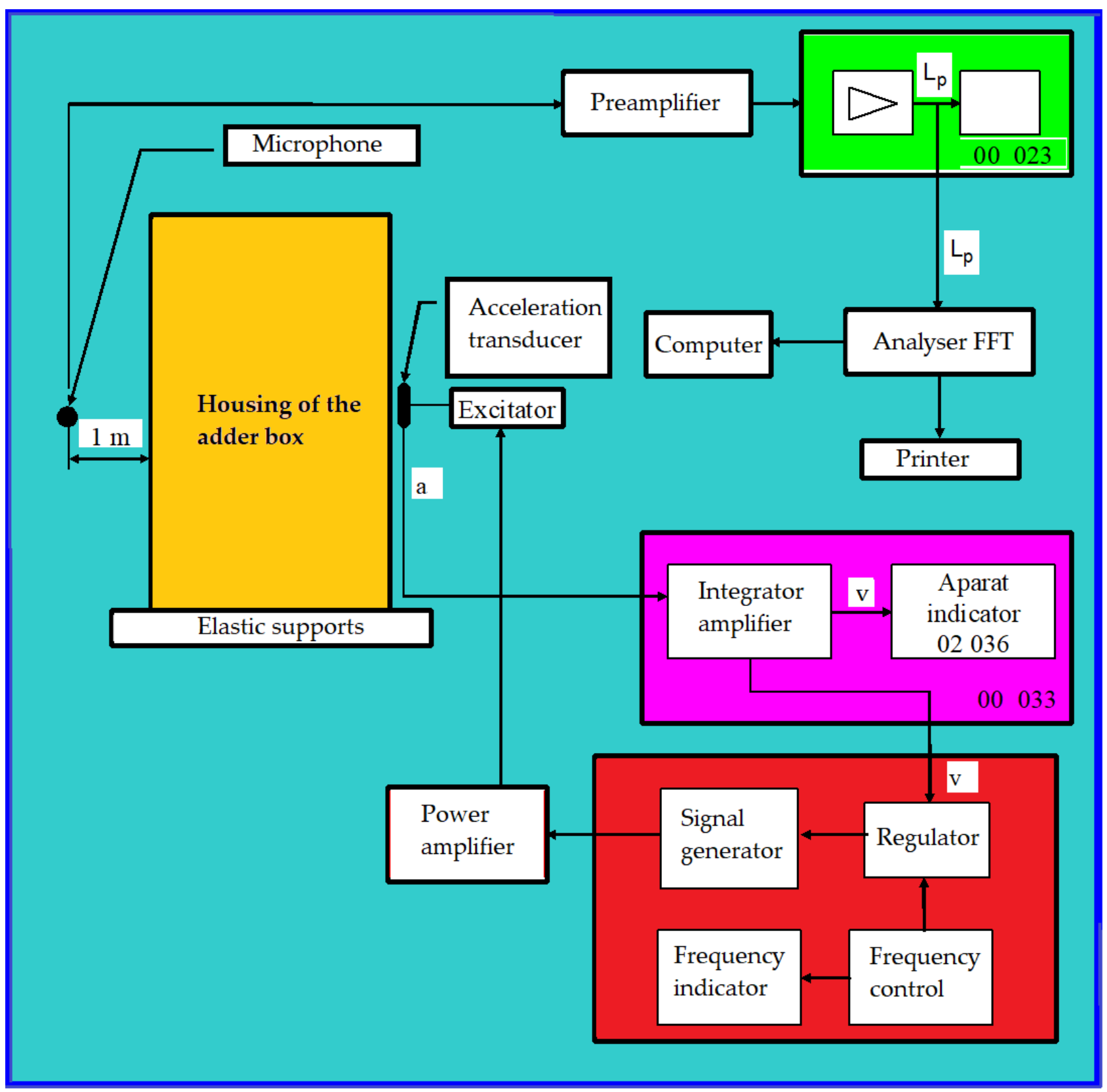

Figure 11. Stand for measurement of sound pressure level radiated. 


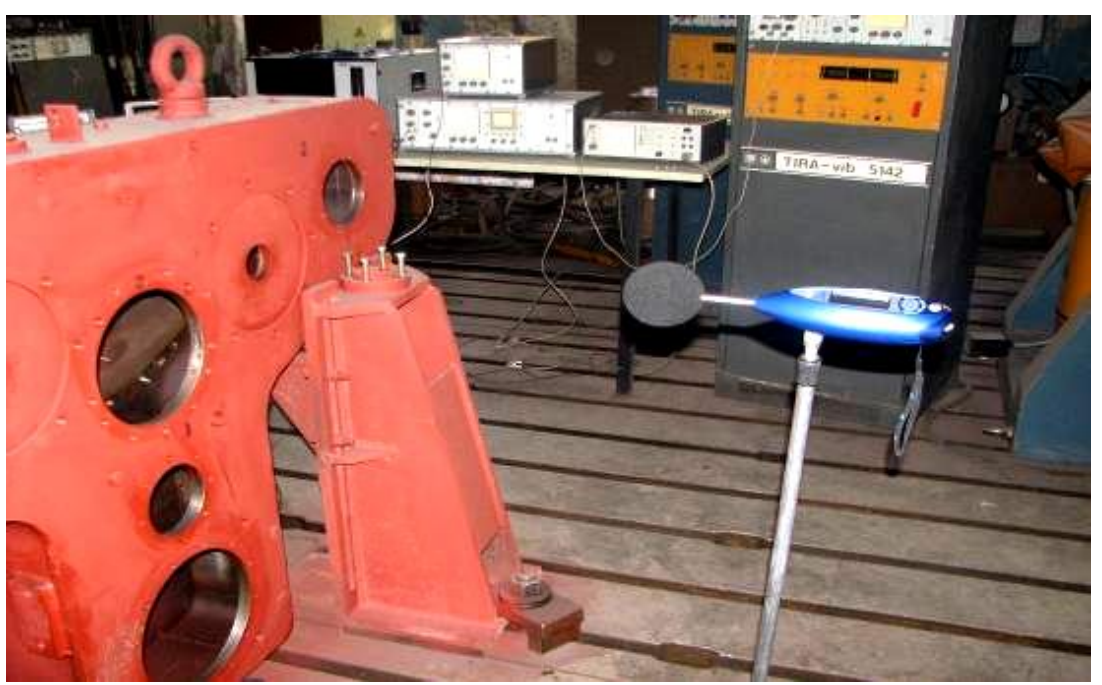

Figure 12. Image of the installation for measuring and analyzing the noise radiated by the housing surfaces.

In the experiment, because the value of the measured sound pressure level was not very important and only the qualitative aspect of the measurement being important, the shape of the obtained spectrum, the simplest measurement method was used. This was imposed by the objective conditions of the experiment, namely the method for measuring the sound pressure level at a distance of $1 \mathrm{~m}$, which is used if the space conditions or the high interferences of the noise level force us to perform the measurements in the vicinity of the object to be measured.

The housing of the adder box was applied with an excitation force applied in the center of the face opposite to that in which the radiated noise is measured, having the following parameters:

- Signal shape: rectangular;

- Constant speed: vex $=4.10^{-3} \mathrm{~m} / \mathrm{s}$ (rms value);

- Exponential back and forth variation of the excitation signal frequency with the speed of $1 \mathrm{oct} / \mathrm{min}$, in two domains: $30 \mathrm{~Hz} \div 500 \mathrm{~Hz}$ with the resolution: $1.25 \mathrm{~Hz} ; 500 \mathrm{~Hz} \div$ $2000 \mathrm{~Hz}$ with the resolution: $5 \mathrm{~Hz}$.

The measurement and analysis of the radiated sound pressure level was performed in real time simultaneously with the frequency variation. The microphone was placed at a distance of $1 \mathrm{~m}$, perpendicular to the analyzed face, opposite to the one to which the excitation force was applied.

The recordings of the linear average power spectral densities of the sound pressure $W p(f)$ obtained at the FFT frequency analyzer, expressed in logarithmic scale in $\mathrm{dB}$, corresponding to the two frequency domains, are presented in the Figures 13 and 14 for the front surface and Figures 15 and 16 for the back surface.

For the analysis of the correlation between the vibrations of the box housing structure and the noise radiated by its surfaces, as well as for the particularization of the resonant frequencies corresponding to the maximum radiated noise, the values of resonant frequencies determined by vibration analysis were compared with the values of frequencies radiated by the respective surfaces.

The calculation ratio of the sound pressure level spectrum $L_{p}(f)$ used by the sound pressure level measuring equipment is:

$$
L_{p}(f)=20 \cdot \log \left[\frac{p(f)}{U_{0}}\right]+110[\mathrm{~dB}]
$$


where $L_{p}(f)$ is the sound pressure level spectrum, in $d B, p(f)$ is the sound pressure spectrum, in volts and $U_{0}=1 \mathrm{~V}$ is the reference voltage.

Figures 13-16 show the spectra of the measured sound pressure levels $L_{p}(f)$ expressed in $\mathrm{dB}$, corresponding to the two frequency ranges.

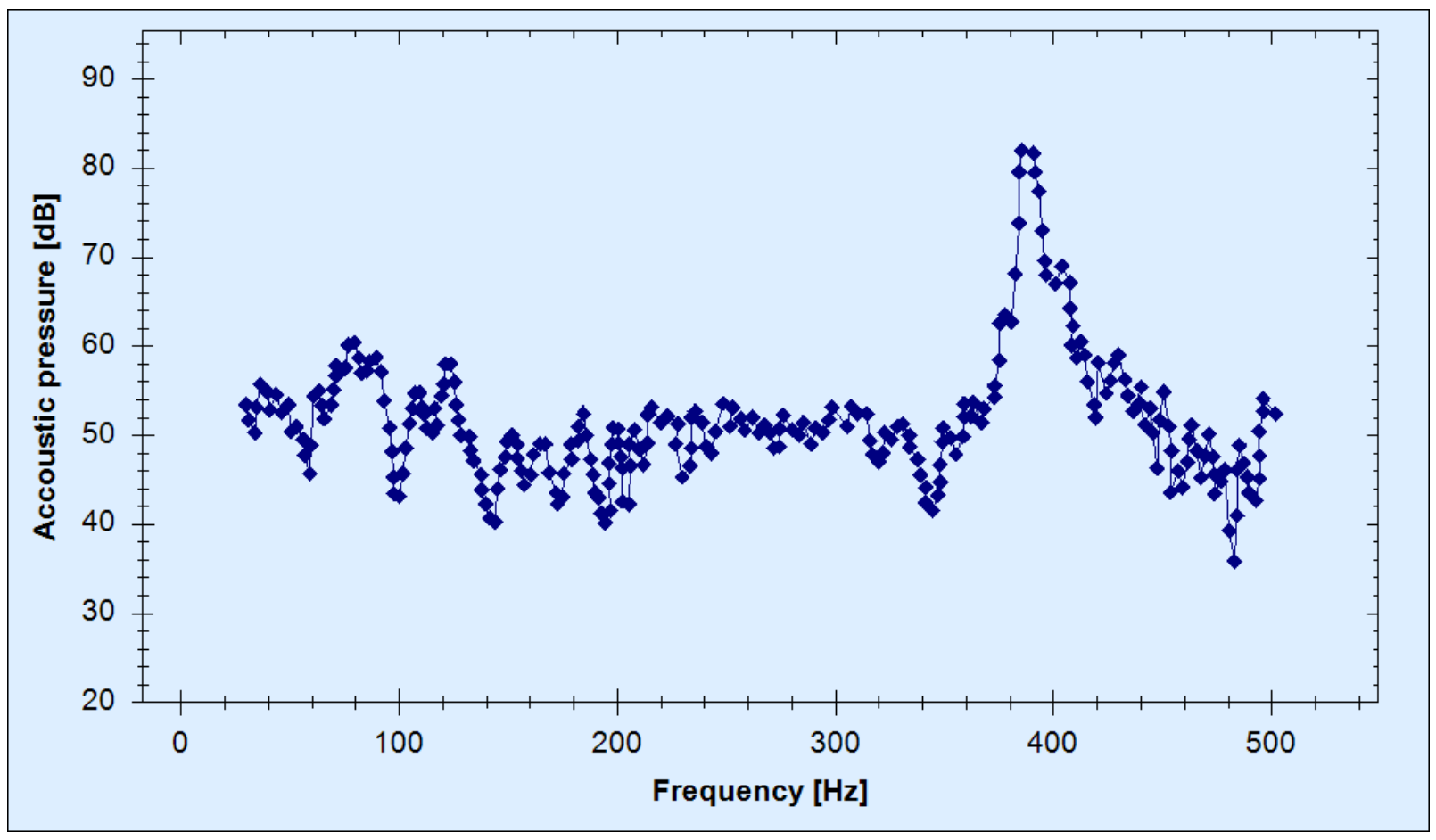

Figure 13. Pressure level for the front surface of the housing; $f=30 \mathrm{~Hz} \div 500 \mathrm{~Hz}$.

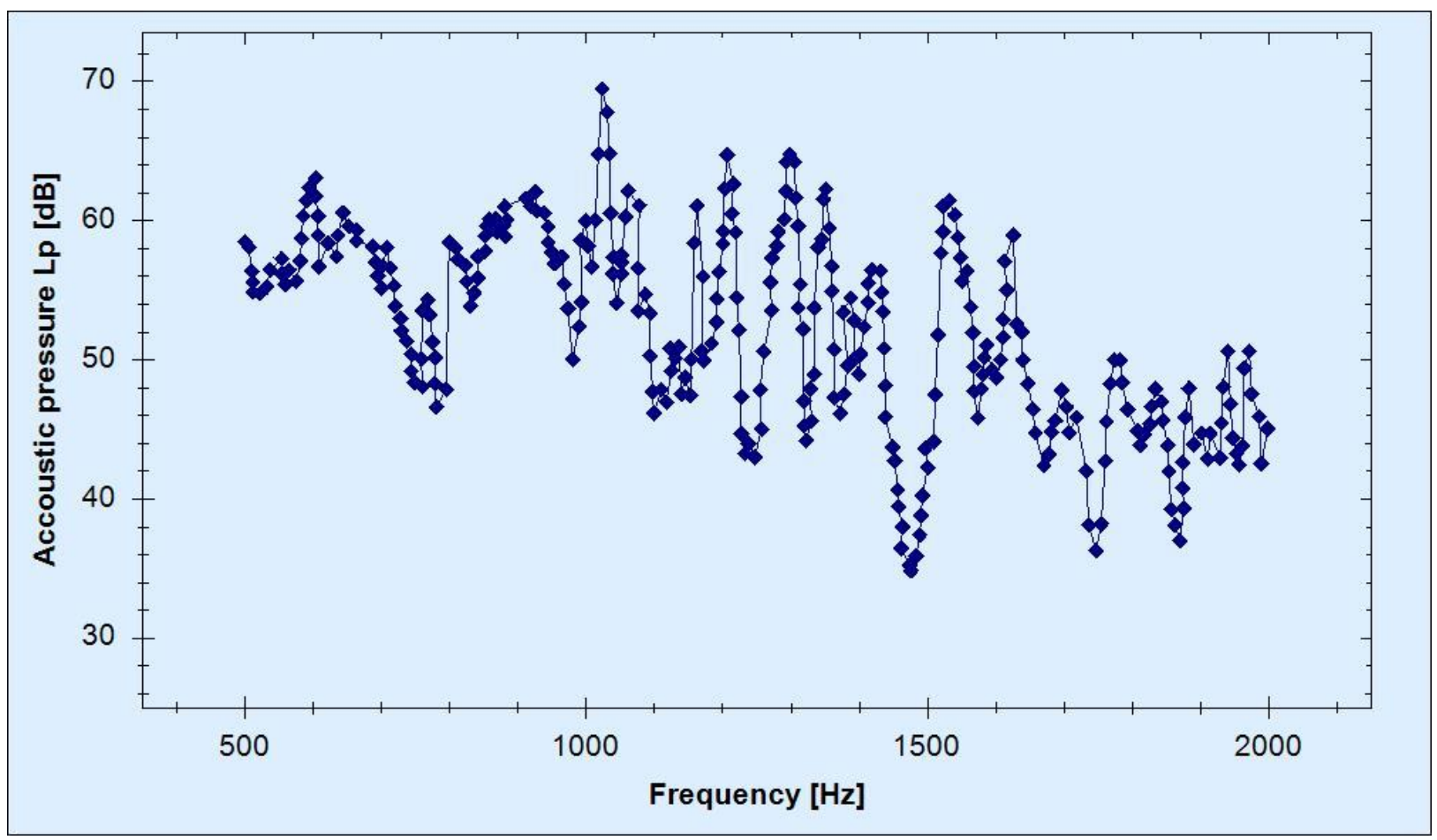

Figure 14. Pressure level for the front surface of the housing; $f=500 \mathrm{~Hz} \div 2000 \mathrm{~Hz}$. 


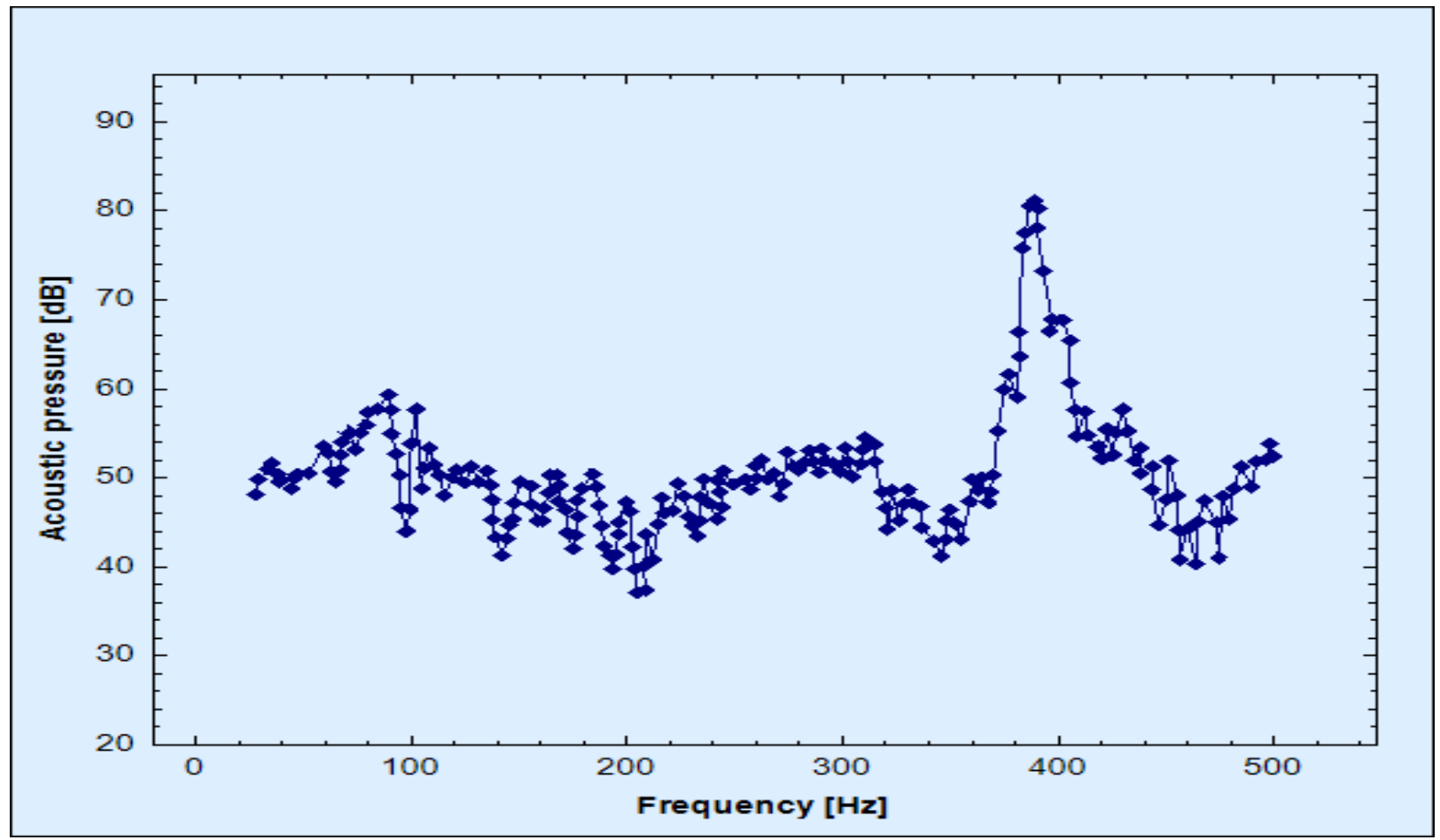

Figure 15. Sound pressure level for the rear surface of the housing; $f=30 \mathrm{~Hz} \div 500 \mathrm{~Hz}$.

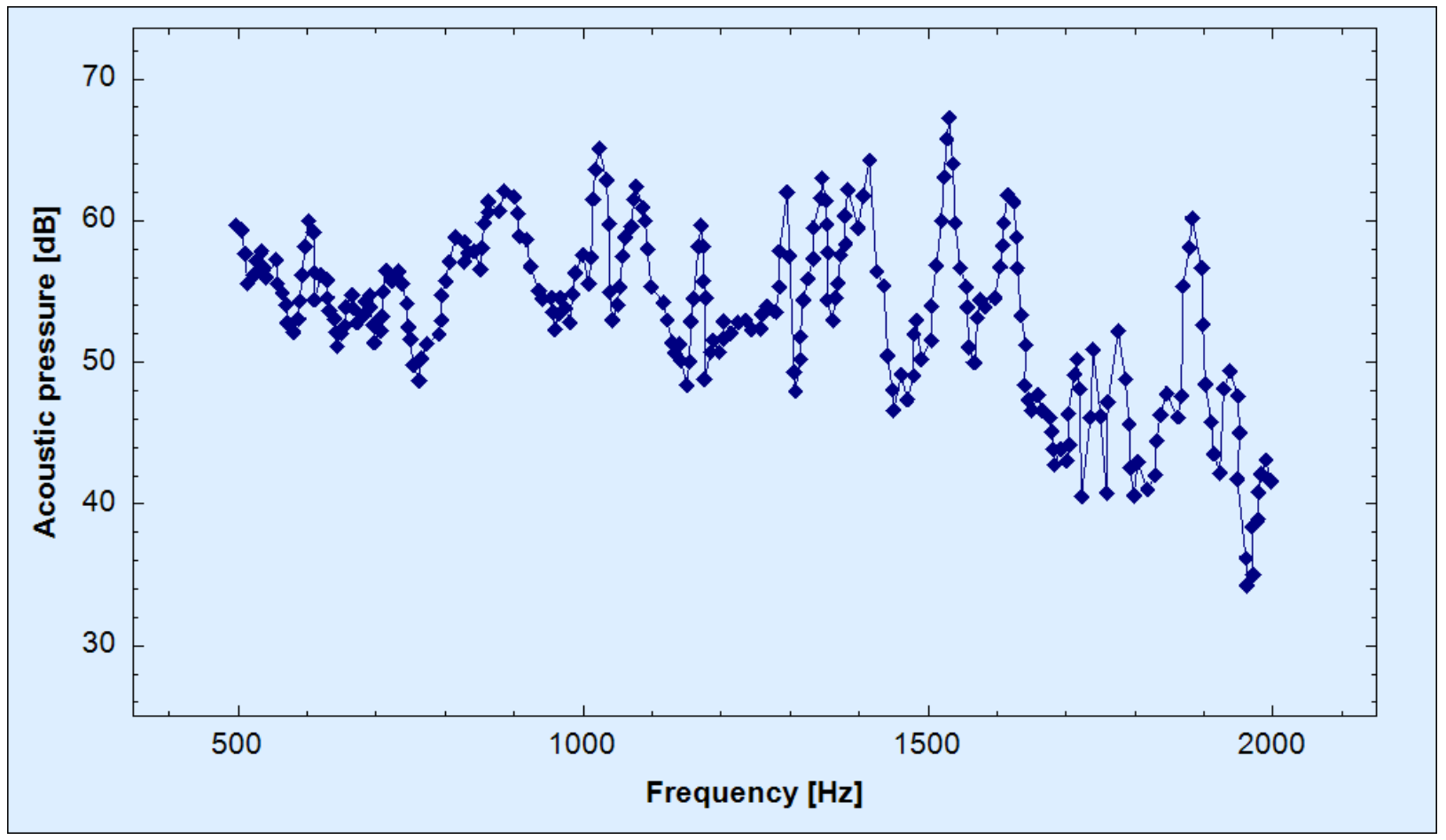

Figure 16. Sound pressure level for the rear surface of the housing; $f=500 \mathrm{~Hz} \div 2000 \mathrm{~Hz}$. 


\subsection{Comparison of the Values of the Resonant Frequencies Obtained Measuring the Mechanical Impedance with the Values of the Sound Pressure Level}

Table 5 presents a comparison of the values of the resonant frequencies determined by measuring the mechanical impedance with the values of the frequencies at which the maximum sound pressure level appear.

Table 5. Comparison of the values of the determined eigenfrequencies.

\begin{tabular}{|c|c|c|c|c|c|}
\hline \multicolumn{3}{|c|}{ Front Surface of the Housing } & \multicolumn{3}{|c|}{ Back Surface of the Housing } \\
\hline \multicolumn{2}{|c|}{ Determined Frequencies } & \multirow[b]{2}{*}{ Differenece } & \multicolumn{2}{|c|}{ Determined Frequencies } & \multirow[b]{2}{*}{ Differenece } \\
\hline $\begin{array}{l}\text { Mechanical } \\
\text { Impedance }\end{array}$ & $\begin{array}{l}\text { Acoustic } \\
\text { Pressure }\end{array}$ & & $\begin{array}{l}\text { Mechanical } \\
\text { Impedance }\end{array}$ & $\begin{array}{l}\text { Acoustic } \\
\text { Pressure }\end{array}$ & \\
\hline$[\mathrm{Hz}]$ & {$[\mathrm{Hz}]$} & [\%] & {$[\mathrm{Hz}]$} & {$[\mathrm{Hz}]$} & {$[\%]$} \\
\hline 395 & 391.5 & 0.89 & 300 & 300 & 0 \\
\hline 400 & 402.5 & -0.62 & 395 & 388 & 1.8 \\
\hline 500 & 499 & 0.2 & 410 & 411.5 & -0.36 \\
\hline 590 & 600 & -1.66 & 435 & 431 & 0.92 \\
\hline 660 & 650 & 1.54 & 495 & 497.5 & -0.5 \\
\hline 720 & 710 & 1.4 & 580 & 600 & -3.33 \\
\hline 1010 & 1010 & 0 & 850 & 875 & -2.85 \\
\hline 1070 & 1065 & 0.46 & 1000 & 1010 & -0.99 \\
\hline 1200 & 1205 & -0.41 & 1125 & 1160 & -3.02 \\
\hline 1300 & 1295 & 0.38 & 1300 & 1298 & 0.15 \\
\hline 1345 & 1345 & 0.00 & 1340 & 1345 & -0.37 \\
\hline 1525 & 1530 & -0.33 & 1550 & 1530 & 1.30 \\
\hline \multirow[t]{2}{*}{1610} & 1600 & 0.62 & 1610 & 1615 & -0.3 \\
\hline & & & 1900 & 1885 & 0.79 \\
\hline
\end{tabular}

Following the analysis of the obtained results, the following statements can be made:

(1) There is a good correlation between the values of eigenfrequencies determined by vibration analysis using the technique of measuring mechanical impedance and the values of eigenfrequencies at which maximum levels of sound pressure radiated by the surfaces of the adder box occur.

(2) From the comparison of the values of the eigenfrequencies included in Table 2 (determined by measuring the mechanical impedance) with the values of the eigenfrequencies included in Table 4 (at which there are maxima of accoustic pressure radiated), it can be observed that more frequencies appear in Table 2. So, eigenfrequencies can be divided into two categories:

- Those that generate maximums of radiated noise (included in Table 4);

- Those that do not generate maximums of radiated noise, as follows.

For the front surface of the box: $230 \mathrm{~Hz} ; 300 \mathrm{~Hz} ; 320 \mathrm{~Hz} ; 765 \mathrm{~Hz} ; 1145 \mathrm{~Hz} ; 1500 \mathrm{~Hz}$.

For the back surface of the box: $200 \mathrm{~Hz} ; 225 \mathrm{~Hz} ; 235 \mathrm{~Hz} ; 280 \mathrm{~Hz} ; 330 \mathrm{~Hz} ; 640 \mathrm{~Hz}$; $1490 \mathrm{~Hz} ; 2000 \mathrm{~Hz}$. From the analysis of the results obtained after performing the presented experiments, the following can be summarized: 
(a) Analysis of the vibration behavior of the housing structure of the summing box (mechanical impedance).

(1) Experimental analysis of vibrations by the method of measuring mechanical impedance has proven to be particularly effective and easy to achieve.

(2) This method allows the analysis of vibration behavior only in a few points of the box housing structure without the need to study the entire structure, the power spectral densities measured on the entire analyzed surface having close values and configurations, which leads to the simplification of the experiment and shortening of analysis time.

(3) The structure of the analyzed box housing presents resonant frequencies approximately in the range of $390 \mathrm{~Hz} \div 2000 \mathrm{~Hz}$ with a dominant frequency of $395 \mathrm{~Hz}$, Figures 7-10 and Table 2.

(b) Experimental determination of noise.

(1) A very good correlation was found between the values of the eigenfrequencies determined by vibration analysis using the impedance measurement technique mechanical, and the values of the frequencies at which maximum pressure levels appear radiated by the surface of the carcass analyzed, with the maximum deviation from the last frequency being $1.8 \%$, Table 5 .

(2) Eigenfrequencies of the analyzed box housing can be divided into two categories:

* Those that generate maximums of radiated noise;

* Those that do not generate maximums of radiated noise.

(3) The fact that there are two distinct categories of resonance vibration modes is a particularly important advantage in terms of the possibility of reducing the running time of acoustic optimization programs. The identification of these vibration modes will be sufficiet to take into account only the frequencies corresponding to the important noise levels, which will lead to a considerable decrease in working time and cost.

\subsection{New Design Solutions for the Adder Box Housing}

The obtained results highlight the important structural deficiencies of the adder box housing analyzed, especially for the rear surface of the housing in the area of the large cap mounted by screws. As a consequence of these observations, we can be propose a new design solution for the adder box housing. In order to stiffen the housing of the adder box, the following constructive changes are proposed:

- Removal of the large cap mounted by screws;

- Replacing the cover with a welded housing plate;

- Inserting inside the housing and mounting by welding two tie rods (reinforcement) between the front surface and the rear surface of the housing in the area of the power take-off;

- Mounting by welding inside, on the side surfaces, front and back, six reinforcing ribs (three on the left and three on the right);

- Cutting and making three manhole covers at the top of the casing necessary for mounting the gears and the wheelhouse of the adder box.

Figure 17 shows a stage in the construction of the new housing. 


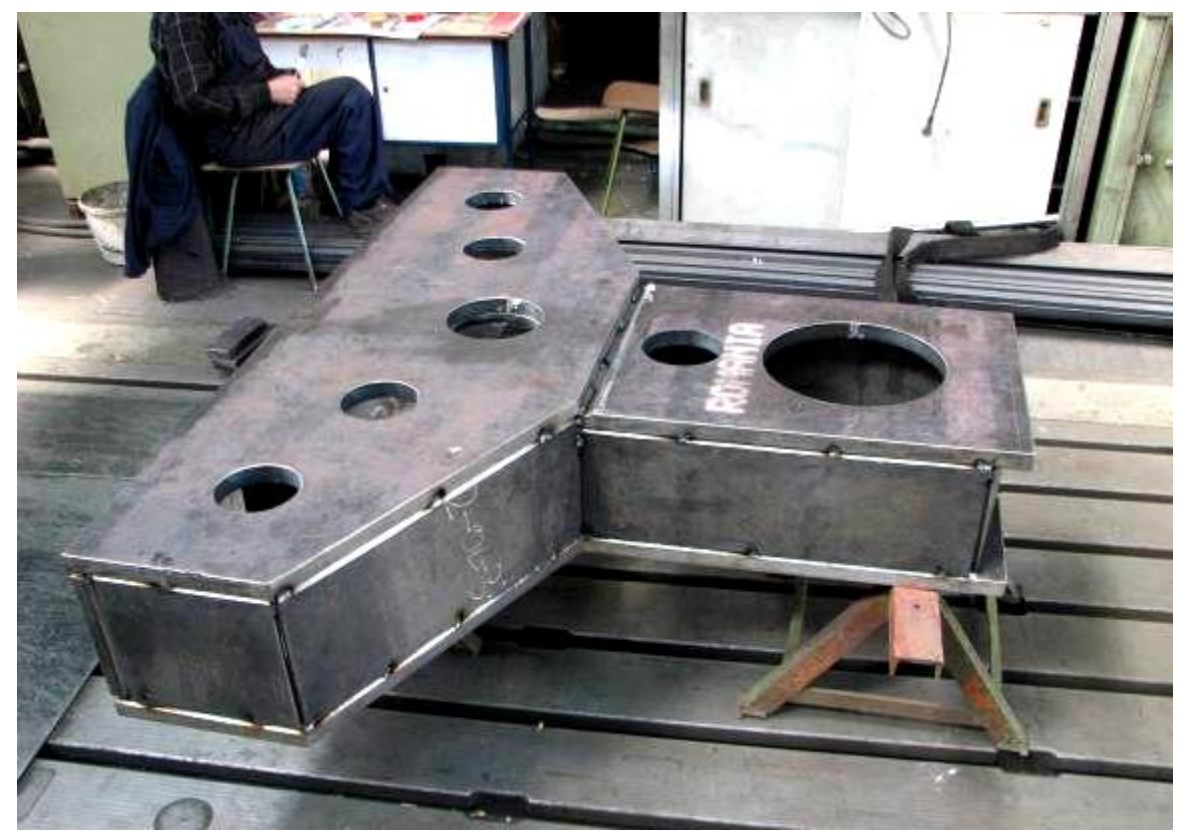

Figure 17. New version of the housing of the adder box.

\section{Discussions}

Section 3 presented the experiments performed on the CSD 4000 adder box housing made in the version with a screw-assembled cap (old version). Based on the analysis of the results of the experiments and the conclusions obtained in operation, the design and realization of an improved housing variant was performed. In this section, we will present comparative experiments of sound pressure, performed on the two adder boxes that we will call below: the old adder box, for the box equipped with the existing housing; and the new adder box, for the box equipped with the improved housing. We mention that the comparative experiments on the two adder boxes were performed under the same test conditions. Measurements of the radiated noise of the box were made one meter away from the four sides of the box.

The measurement and experimental analysis of the radiated noise (sound pressure level) from the surfaces of the adder boxes on the old version and new version (Figure 18) were performed during the running program (without load) on the stand. In the experiment, as the value of the measured sound pressure level is not very important and only the qualitative aspect of the measurement is important, the shape of the obtained spectrum, the simplest measurement method was used. This was imposed by the objective conditions of the experiment, namely the method for measuring the sound pressure level at a distance of $1 \mathrm{~m}$, which is used if the space conditions or the high interferences of the noise level force us to perform the measurements in the vicinity of the object to be measured (Figure 19).

Figure 20 shows an example of measuring noise at a distance of $1 \mathrm{~m}$ from the side surface of the box.

The aim of the experiment was to conduct a comparison between the radiated noise in the case of the old version of the adder box and the new version. The measurement and analysis of the radiated sound pressure level was performed in real time for four speed regimes. The microphone was placed at a distance of $1 \mathrm{~m}$ from each surface of the box and at a height of $1.2 \mathrm{~m}$. Recordings of the power spectral densities of the sound pressure $W p(f)$ were obtained and recorded by the sonometer for $1 \mathrm{~min}$, processed and expressed in logarithmic scale in dB. The pressure level is presented in the Figure 21. 


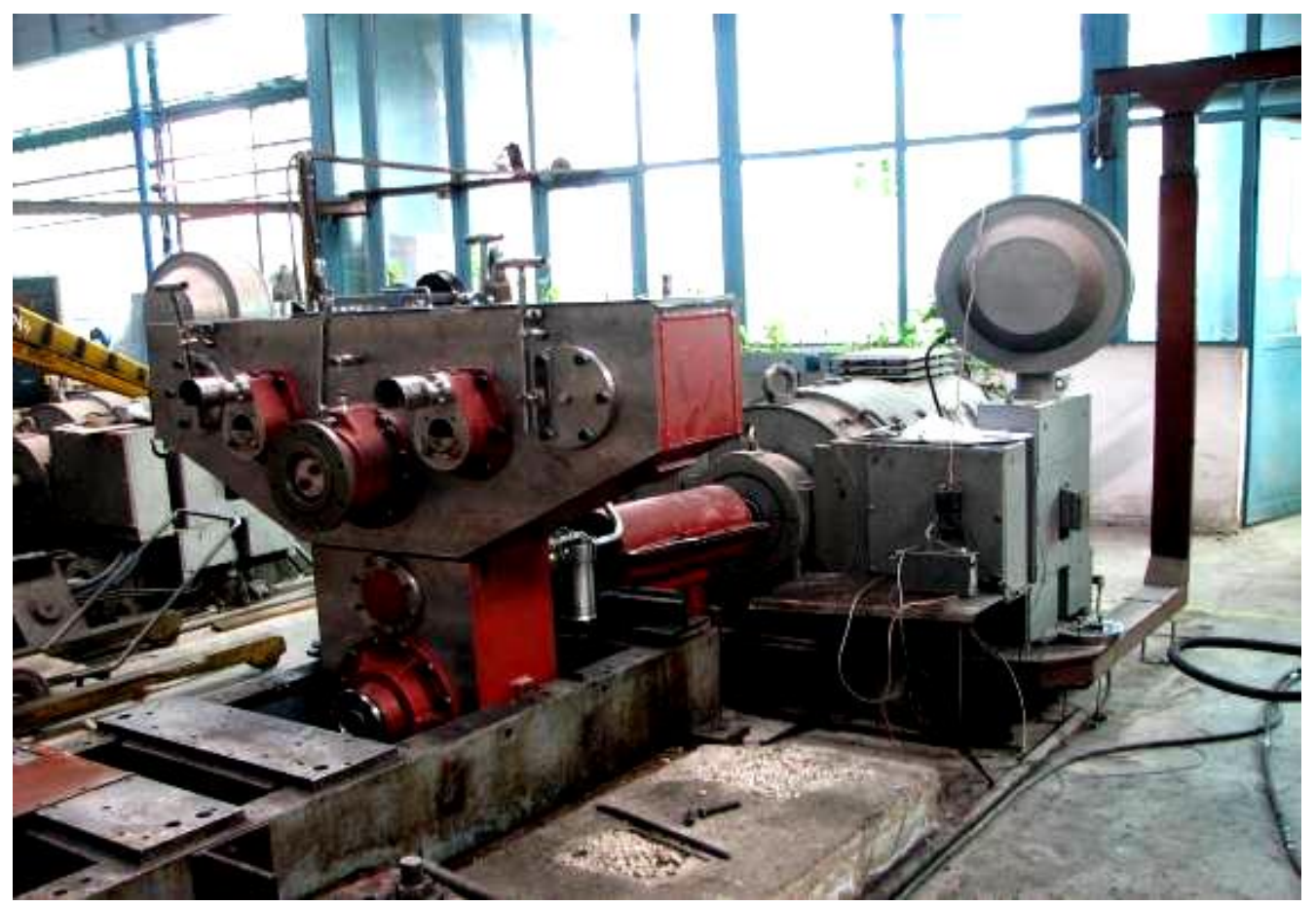

Figure 18. New adder box on experimental stand.

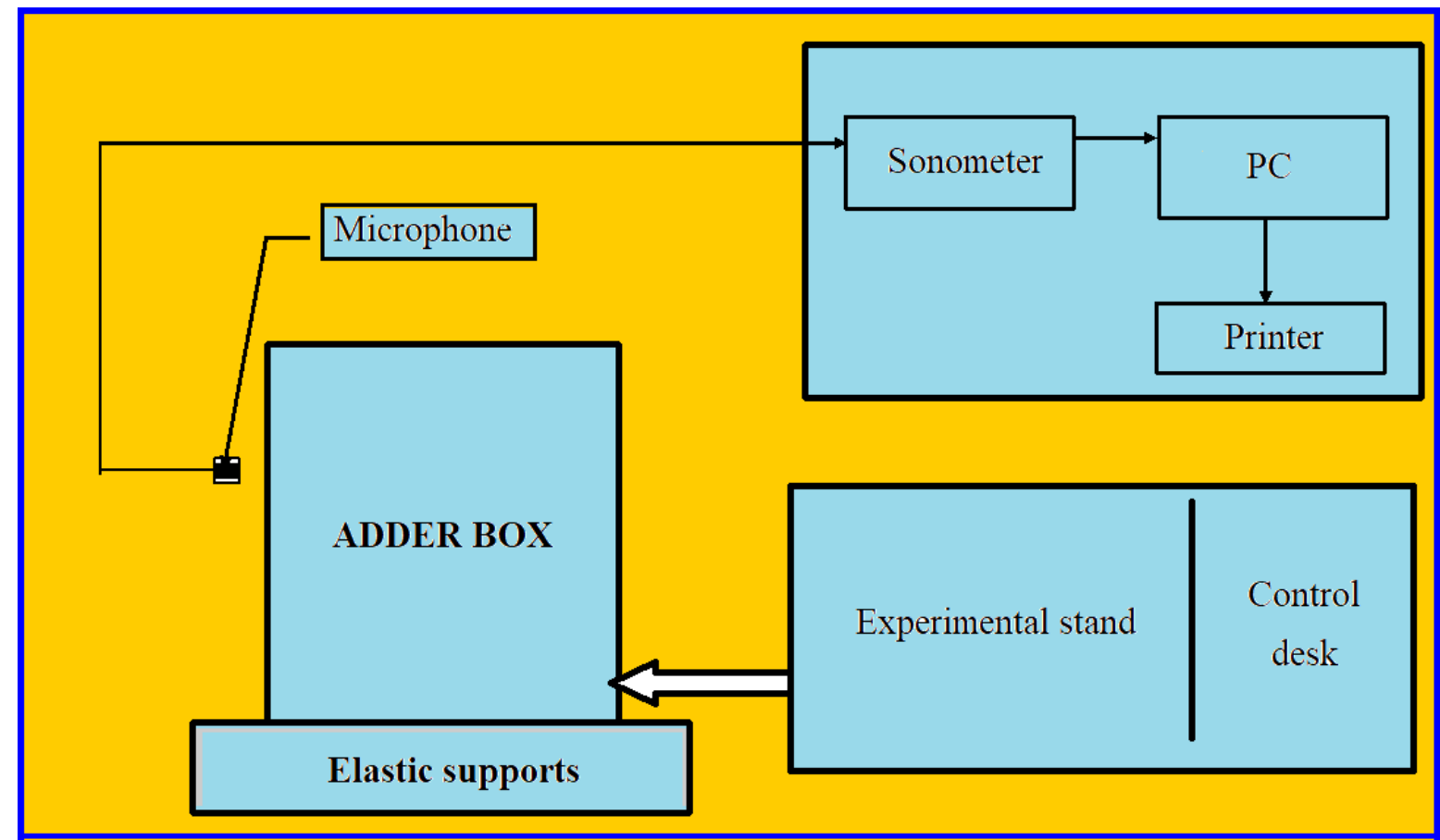

Figure 19. Block diagram of the experimental setup for measuring and analyzing the noise radiated by the surfaces of the adder box. 


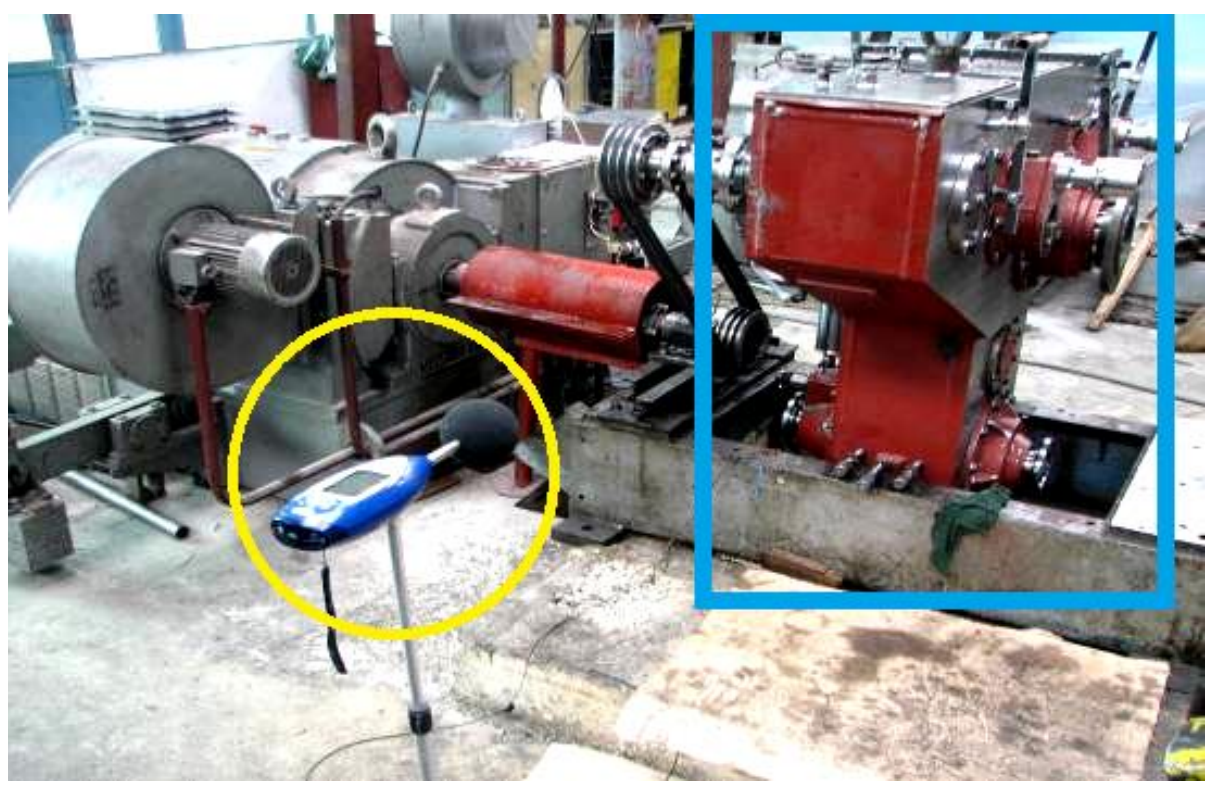

Figure 20. The experimental setup for measuring and analyzing the noise radiated by the surfaces of the adder box. Yellow circle: sonometer; blue rectangle: adder box, new version.

The new constructive solutions adopted led to the following results:

* By removing the large cover assembled by screws, inserting the tie rods and reinforcing plates inside the housing, the new variant of the housing structure was stiffened, a proposed objective for reducing the structural noise of the housing;

* The vibration level of the structure and implicitly of the adder box as a whole was reduced;

* The noise produced by the adder box in the new version decreased, on average, by $10-15 \%$ compared to the noise produced by the adder box in the old version;

* A constancy was obtained within limits $(70-75 \mathrm{~dB})$ of the noise level produced by the new version adder box compared to the old version adder box;

* A simplification of the manufacturing technology was obtained and implicitly a reduction in the labor and of the assembly time of the adder box;

* A reduction in the mass of the adder box was obtained with the new variant by approximately $5 \%$ in this phase.

It can be stated that by applying the experimental method presented in the process of optimizing the housing of the adder box by structural measures, the following findings were obtained:

$>$ There is the possibility to determine without difficulty and with sufficient precision the resonance frequencies corresponding to the important vibration modes generating structural noise radiated by the chassis surfaces;

$>$ Resonant frequencies and maximums of the radiated noise spectrum can be predicted from the design stage with a maximum accuracy of only a few $\mathrm{dB}$.

$>$ Although the application of this experimental method does not require special conditions, and the measurement and analysis equipment does not imply a special complexity, it still provides the necessary accuracy required by the structural acoustic optimization. 

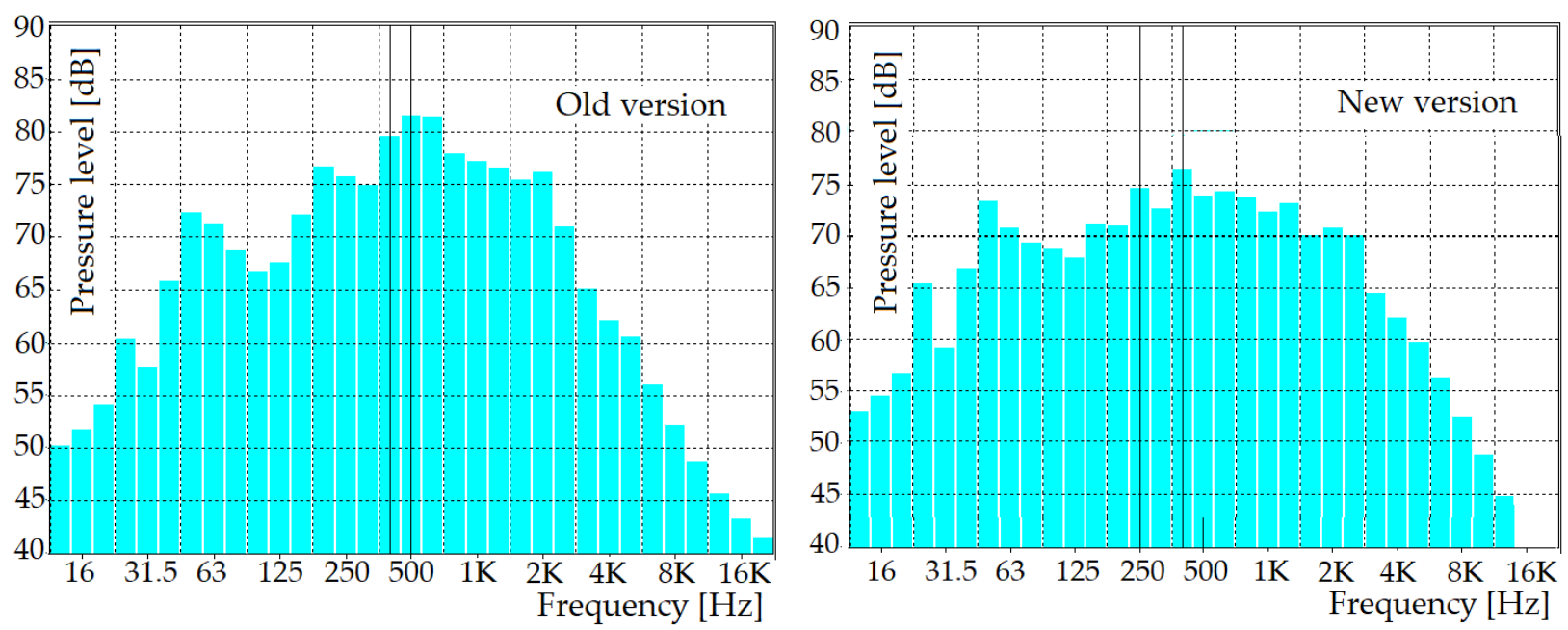

(a)
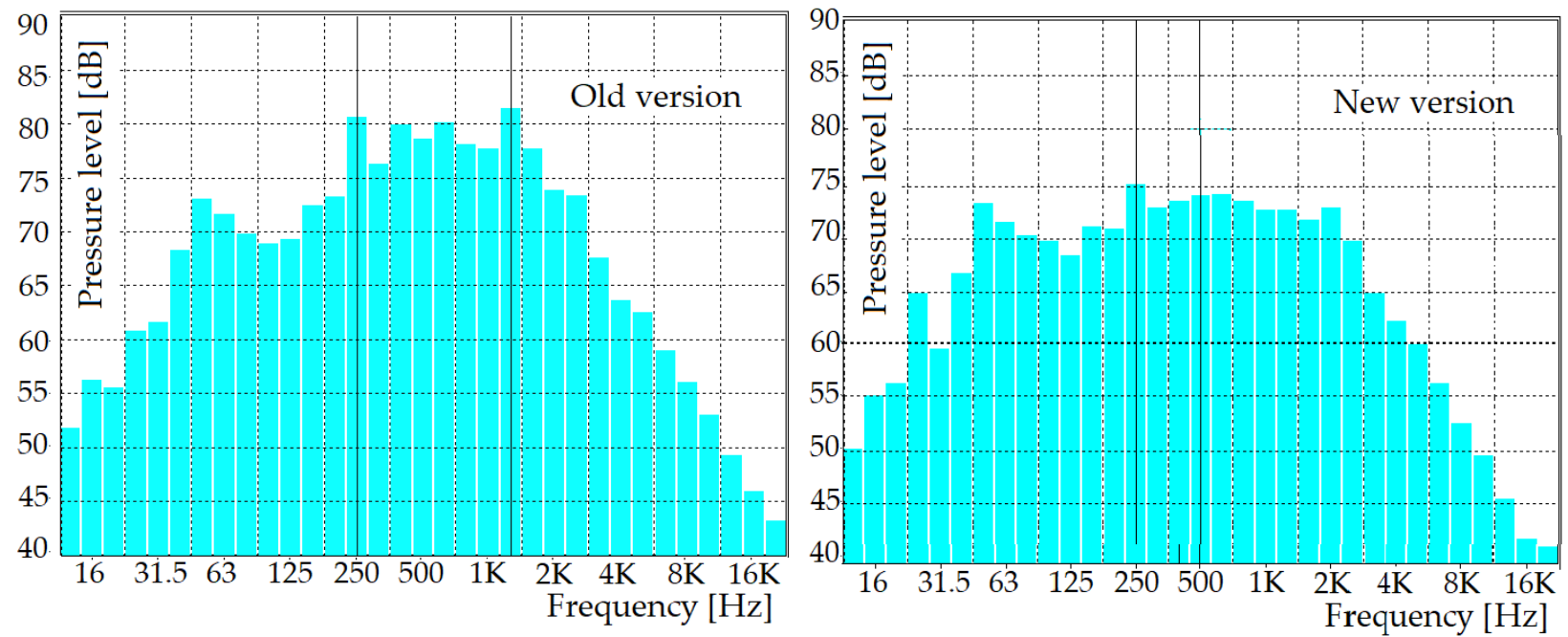

(b)
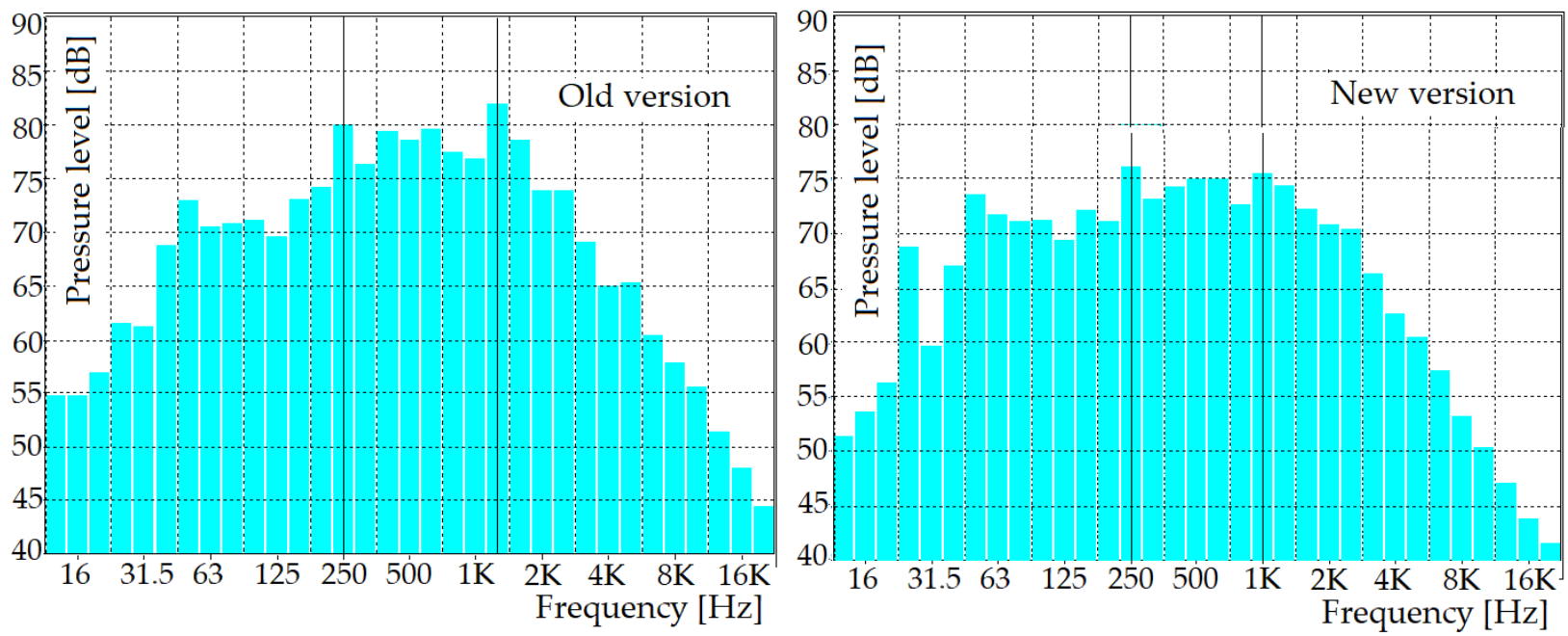

(c)

Figure 21. Cont. 

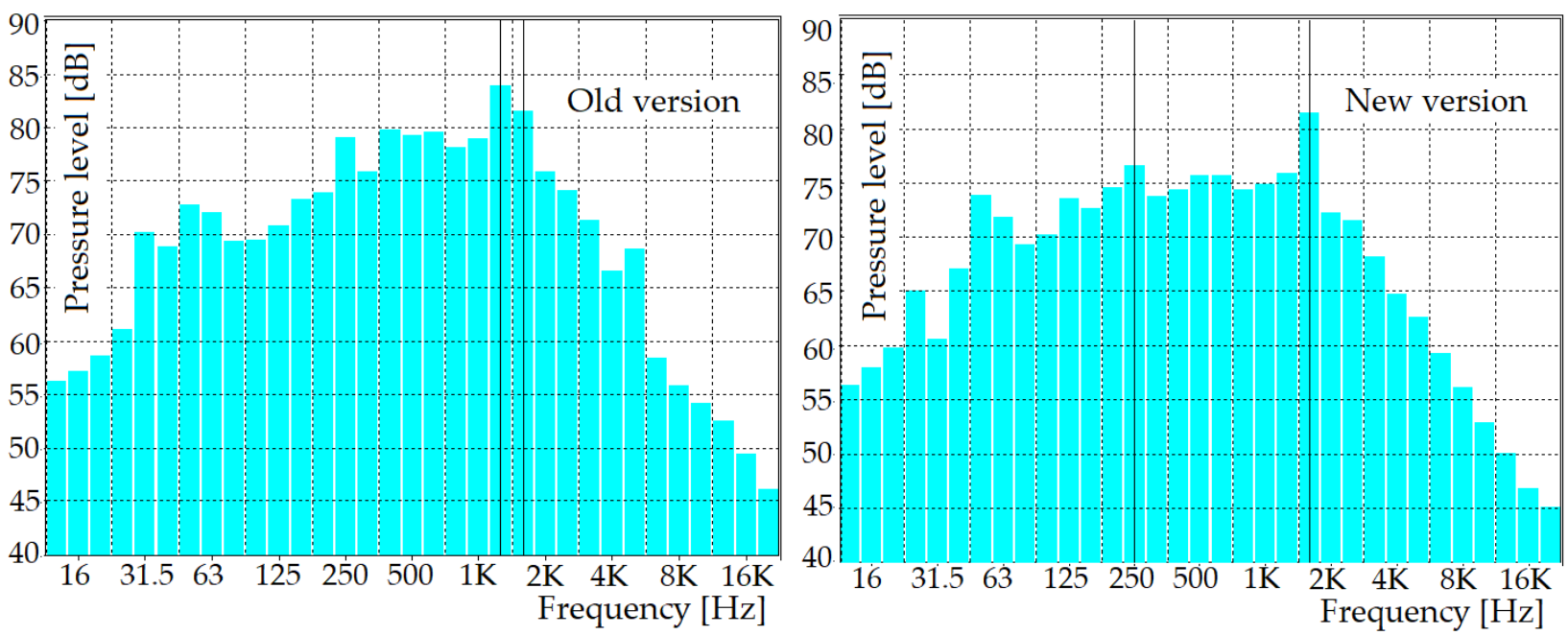

(d)

Figure 21. Sound pressure level spectra $L p$ (front surface of the box). (a) $500 \mathrm{rot} / \mathrm{min}$; (b) $1000 \mathrm{rot} / \mathrm{min}$; (c) $1500 \mathrm{rot} / \mathrm{min}$; (d) $2000 \mathrm{rot} / \mathrm{min}$.

\section{Conclusions}

The vehicle is a complex mechanical system that, during operation, generates a wide spectrum of vibrations. Much of their energy is radiated outward in the form of sound waves (noise). The problem of reducing the noise generated by vehicles is an objective of great interest in the world of designers and manufacturers, seen in terms of reducing noise pollution and increasing the reliability of vehicles. The reduction in the structural noise of the components creates not only the reduction in the air noise but also the increase in the reliability, with defects such as cracks, deformations, misalignments, etc. being diminished or even eliminated.

The experimental evaluation of the radiated noise presents a major importance, on the one hand both in the appreciation of the noise sources, but also in the appreciation of the factors that, from the design phase, can be chosen in order to attenuate the housing noise.

Determination by calculation of structural and radiated noise is extremely difficult, being possible only for sources with simple geometric shapes. For this reason, in the paper, experimental determinations were made, followed by the comparison of the obtained results.

Solutions for stiffening the housing structure were proposed, resulting in a reduction in its structural noise. The design and construction of the housing in the improved version required the validation of the constructive solution. Thus, comparative tests were performed on the test stand for both housing variants (existing and improved). The test results showed that by stiffening the box housing, the vibration level was reduced, and, implicitly, the structural noise of the summing box housing was reduced.

The group of authors, in an effort to analyze a new variant of adder box compared to the old version, found that the costs required to perform vibration measurements were significantly higher than in the case of direct noise measurement. Furthermore, the measurements in the second case were much simpler and much faster. Consequently, we believe that a noise analysis can give a correct and low-cost picture of the vibration behavior of such a structure.

As a result of the research, the paper presents an improved design of an adder box, which carries a lower weight and at the same time ensures a lower noise level. If an extension of the results obtained to other types of vehicles is desired, this must be completed with care because the structures of the different vehicles can be very different. As a result, the generation and transmission of vibrations can be very different. However, the methods 
used can be used to study gearboxes, adder boxes or distribution boxes with similar properties.

Author Contributions: Conceptualization, S.V.; methodology, A.B., M.L.S., M.M., S.V. and A.T.; software, M.L.S. and A.T.; validation, A.B., S.V. and M.M.; formal analysis, A.B., M.L.S. and M.M.; investigation, A.B., S.V.; resources, S.V.; data curation, A.B. and S.V.; writing-original draft preparation, S.V.; writing—review and editing, S.V. and M.M.; visualization, M.L.S., S.V. and M.M.; supervision, S.V.; project administration, S.V. and M.M.; funding acquisition, S.V. All authors have read and agreed to the published version of the manuscript.

Funding: The APC was funded by the Transilvania University of Brasov.

Institutional Review Board Statement: Not applicable.

Informed Consent Statement: Not applicable.

Data Availability Statement: Not applicable.

Conflicts of Interest: The authors declare no conflict of interest.

\section{Nomenclature}

$\begin{array}{ll}p_{r m s} & \text { Sound pressure } \\ I_{m a x} & \text { Maximum intensity } \\ \omega_{n} & \text { Eigenfrequencies } \\ D_{j n} & \text { Configuration of normal vibration modes } \\ c & \text { Damping coefficient } \\ \mathcal{C}_{\mathcal{C}} & \text { Critical damping coefficient } \\ S_{\mathrm{S}} & \text { Fraction of the critical damping } \\ R g & \text { Amplification factor } \\ W_{s} & \text { Acoustic power } \\ Z & \text { Mechanical impedance } \\ L_{p r} & \text { Sound pressure level }\end{array}$

\section{References}

1. Soami, P. Modeling Vibration and Noise in a Gearbox. Mech. Eng. 2018, 140, $22-24$.

2. Vlase, S.; Marin, M.; Scutaru, M.L.; Munteanu, R. Coupled transverse and torsional vibrations in a mechanical system with two identical beams. AIP Adv. 2017, 7, 065301. [CrossRef]

3. Elisabeth, K.; John, L.; Lars, H.; Magnus, K.; Jing, L. Vibration-based Condition Monitoring of Heavy Duty Machine Driveline Parts: Torque Converter, Gearbox, Axles and Bearings. Int. J. Progn. Health Manag. 2019, 10, 14. [CrossRef]

4. Wu, H.; Wu, P.B.; Xu, K.; Li, J.C.; Li, F.S. Research on Vibration Characteristics and Stress Analysis of Gearbox Housing in High-Speed Trains. IEEE Access 2019, 7, 102508-102518. [CrossRef]

5. Batizi, V.; Likhachev, D. Mass-geometric parameters improvement of gearbox by using vibration analysis. In Proceedings of the 14th International Conference on Vibration Engineering and Technology of Machinery (VETOMAC XIV), Lisbon, Portugal, 10-13 September 2018; Volume 211, p. AR 06002. [CrossRef]

6. Guo, W.; Chen, C.; Xiao, N.C. Dynamic vibration feature analyses for a two-stage planetary gearbox with a varying crack using a rigid-flexible coupled model. J. Intell. Fuzzy Syst. 2018, 34, 3869-3880. [CrossRef]

7. Furch, J.; Glos, J.; Nguyen, T.T. Modeling and Simulation of Mechanical Gearbox Vibrations. In Proceedings of the International Conference 20th International Scientific Conference on Transport Means, Juodkrante, Lithuania, 5-7 October 2016; pp. 133-139.

8. Kucukay, F.; Pfeiffer, F. Clattering Vibrations in Gearboxes of Motor-Vehicles. Ing. Arch. 1986, 56, 25-37. [CrossRef]

9. Astridge, D.G. Gearbox Noise and Vibration—Review of Opportunities for Improving Safety and Reliability. In Proceedings of the 1st International Conference on Gearbox Noise and Vibration, Institution of Mechanical Engineers Series, Cambridge, UK, 9-11 April 1990; pp. 11-18.

10. Vlase, S. A Method of Eliminating Lagrangian-Multipliers from the Equation of Motion of Interconnected Mechanical Systems. J. Appl. Mech. Trans. ASME 1987, 54, 235-237. [CrossRef]

11. Vlase, S.; Teodorescu, P.P. Elasto-Dynamics of a Solid with a General "Rigid" Motion using FEM Model Part I. Theoretical Approach. Rom. J. Phys. 2013, 58, 872-881.

12. Scutaru, M.L.; Vlase, S.; Marin, M.; Modrea, A. New analytical method based on dynamic response of planar mechanical elastic systems. Bound. Value Probl. 2020, 2020, 104. [CrossRef] 
13. Wang, Q.; Shen, R.Y. Study on Vibration \& Noise of Gearbox. In Proceedings of the 14th International Congress on Acoustics (ICA 14), Beijing, China, 3-10 September 1992; Volumes 1-4, pp. 679-680.

14. Tuma, J. Analysis of Gearbox Vibration in Time Domain. In Proceedings of the Institute of Acoustics, Euro Noise 92, London, UK, 14-18 September 1992; Volume 14, pp. 597-604.

15. Choy, F.K.; Ruan, Y.F.; Tu, Y.K.; Zakrajsek, J.J.; Townsend, D.P. Modal-Analysis of Multistage Gear Systems Coupled with Gearbox Vibration. J. Mech. Des. 1992, 114, 486-497. [CrossRef]

16. Sargeant, M.; Stone, B.J. Coupled torsional and transverse vibration of gearboxes. In Proceedings of the 3rd International Symposium on Multi-Body Dynamics -Monitoring and Simulation Techniques, Loughborough, UK, 12-13 July 2004; pp. 299-309.

17. Guan, Y.H.; Shepard, W.S.; Lim, T.C.; Li, M. Experimental analysis of an active vibration control system for gearboxes. Smart Mater. Struct. 2004, 13, 1230-1237. [CrossRef]

18. Guan, Y.H.; Lim, T.C.; Shepard, W.S. Experimental study on active vibration control of a gearbox system. J. Sound Vib. 2005, 282, 713-733. [CrossRef]

19. Li, M.F.; Lim, T.C.; Shepard, W.S.; Guan, Y.H. Experimental active vibration control of gear mesh harmonics in a power recirculation gearbox system using a piezoelectric stack actuator. Smart Mater. Struct. 2005, 14, 917-927. [CrossRef]

20. Ploger, D.; Zech, P.; Rinderknecht, S. Experimental identification of high-frequency gear mesh vibrations in a planetary gearbox. In Proceedings of the International Conference on Noise and Vibration Engineering (ISMA)/International Conference on Uncertainty in Structural Dynamics (USD), Leuven, Belgium, 19-21 September 2016; pp. 911-924.

21. Benaroya, H.; Mark Nagurka, M.; Han, S. Mechanical Vibration; CRC Press: Boca Raton, FL, USA, 2017. 